Simulação de fluido multifásico em imagens digitais Alex da Silva Gimenes 
SERVIÇO DE PÓS-GRADUAÇÃO DO ICMC-USP

Data de Depósito:

Assinatura:

\title{
Simulação de fluido multifásico em imagens digitais
}

\author{
Alex da Silva Gimenes \\ Orientador: Prof. Dr. Luis Gustavo Nonato
}

Dissertação apresentada ao Instituto de Ciências Matemáticas e de Computação - ICMC-USP, como parte dos requisitos para obtenção do título de Mestre em Ciências - Ciências de Computação e Matemática Computacional.

USP - São Carlos

Janeiro/2008 
Às pessoas que mais amo nessa vida, minha família, dedico. 


\section{Agradecimentos}

Primeiramente a Deus, pela oportunidade da vida.

À FAPESP pelo suporte financeiro, sem o qual não seria possível a conclusão deste trabalho.

A meus pais Antônio e Ivanilde, minha irmã Alessandra e minha linda sobrinha Miel Jasmin pela compreensão de minha ausência nesses anos que se passaram. Eu não seria o mesmo sem cada um de vocês.

Aos professores Drs. Suetônio de Almeida Meira, José Roberto Nogueira e Messias Meneguette Jr. da FCT/UNESP de Presidente Prudente/SP, por todo ensinamento, dedicação e amizade desde os tempos do curso de graduação.

A todos os colegas do LCAD, em especial João Paulo, Valdecir, Mario, Renato e Alexandre por suas amizades, pela troca de informações e pela importante ajuda nos momentos de dificuldade. Aos colegas dos tempos de graduação, em especial à Evelise, à Aline Soterroni, à Ana Pivem, à Luciana e ao Marcos Tófano, por tudo de bom que nossa amizade nos trouxe. Aos amigos Claudio, Glauber, Juliano Oliveira, Marcos Pimenta, José Jamil, Bruno, Fernando Balzaneli e ao meu primo Juliano pelo companheirismo e por todos os bons momentos compartilhados. Aos novos amigos Marcus, Juliano Oler, Yuri, Rodrigo e Dusse pelos momentos de descontração e sadia convivência.

Aos professores do LCAD, especialmente a meu orientador, professor Dr. Luis Gustavo Nonato, exemplo de dedicação e competência. Serei sempre grato por sua orientação, amizade e acompanhamento durante o desenvolvimento das etapas do trabalho. 
"De onde vem essa busca? Essa necessidade de resolver os mistérios da vida, quando as mais simples questões podem não ser respondidas? Talvez fosse melhor nem procurarmos. Não aprofundar. Não ansiar.

(...)

Mas ainda sim nos esforçamos para fazer a diferença, contribuir por um mundo melhor e sonhar com esperança, nunca tendo a certeza de quem encontraremos pelo caminho, quem dentre os estranhos vai segurar nossa mão, tocar nossos corações e compartilhar a dor de tentar.

$(\ldots)$

E então acontece. O sonho vira realidade e a resposta para esta jornada, essa necessidade de resolver os mistérios da vida finalmente aparece como a brilhante luz de uma nova aurora. Tanto esforço por um significado, um propósito e, no fim, nós encontramos isso em cada parte, nossa experiência compartilhada do fantástico e do mundano, a simples necessidade humana de se relacionar, saber dentro de nossos corações que não estamos sozinhos e que, finalmente, o que realmente importa é a felicidade, a paz e o amor."

Tim Kring (adaptado) 


\section{Abstract}

In the last years, fluid simulation has been one of the main focus in Computer Graphics. Such a reason is related to applications to film industry, games and frameworks for realtime physical problem simulations. In this work we aim at accessing a problem which is not so much explored in Computer Graphics: fluid simulation in digital images. We adopt a approach related to multiphase fluids, where properties of the image are set to the Navier-Stokes equations in order to allow that objects into the images "flow" in accordance to the forces in the system. 


\section{Resumo}

Simulação de fluidos tem sido um dos focos principais de pesquisa em computação gráfica nos últimos anos. O interesse por tal assunto é motivado pelas aplicações na indústria cinematográfica, jogos e sistemas voltados para simulação de fenômenos físicos realísticos em tempo real. Neste trabalho atacamos um problema ainda pouco explorado pela comunidade de computação gráfica, a simulação de fluidos em imagens digitais. Adotamos uma abordagem relacionando fluidos multifásicos, onde propriedades da imagem são incorporadas às equações de Navier-Stokes a fim de permitir que objetos contidos nas imagens "escoem" interagindo a forças que agem no sistema. 


\section{Conteúdo}

Conteúdo $\quad$ i

1 Introdução 1

2 Revisão Bibliográfica 5

2.1 Preliminares . . . . . . . . . . . . . . . . . 5

2.1.1 EDP's e processamento de imagens . . . . . . . . . . . . . . . 5

2.1.2 Dinâmica dos Fluidos Computacional . . . . . . . . . . . . . . . 7

2.2 Fluidos em Computação Gráfica . . . . . . . . . . . . . . . . . . . 10

2.3 Fluidos em Imagens . . . . . . . . . . . . . . . . . . . . . . 16

3 Fluidos estáveis $\quad 23$

3.1 Método das características . . . . . . . . . . . . . . . . 23

3.2 Teorema da decomposição de Helmholtz-Hodge . . . . . . . . . . . . . . 24

3.3 O método estável de Stam . . . . . . . . . . . . . . . . . 26

3.3.1 Ambiente computacional . . . . . . . . . . . . . 26

3.3.2 Atualização do campo de velocidades . . . . . . . . . . . . . 28

3.3.3 Movendo substâncias no fluido . . . . . . . . . . . . . . . . . 31

4 Fronteira Imersa $\quad 35$

4.1 Domínio computacional . . . . . . . . . . . . . 36

4.2 O termo forçante . . . . . . . . . . . . . . 38 
Conteúdo

4.3 Aproximação forçante contínua . . . . . . . . . . . . . . . . . . . . . 41

4.3.1 Fronteiras elasticamente deformáveis . . . . . . . . . . . . . . . 41

4.3 .2 Fronteiras rígidas . . . . . . . . . . . . . . . . . . 43

4.4 Aproximação forçante discreta . . . . . . . . . . . . . . . . . . . . . . 44

4.4.1 Imposição indireta da condição de contorno . . . . . . . . . . . . . 44

$\begin{array}{lll}5 & \text { Resultados } & 47\end{array}$

5.1 Estrutura do solver . . . . . . . . . . . . . . . . . . . 47

5.2 Viscosidade constante . . . . . . . . . . . . . . . . . . . . 49

5.3 Viscosidade variável . . . . . . . . . . . . . . . . . . . . . . 54

6 Conclusão $\quad 61$

A Método dos gradientes bi-conjugados $\quad 63$

$\begin{array}{ll}\text { Referências Bibliográficas } & 65\end{array}$ 


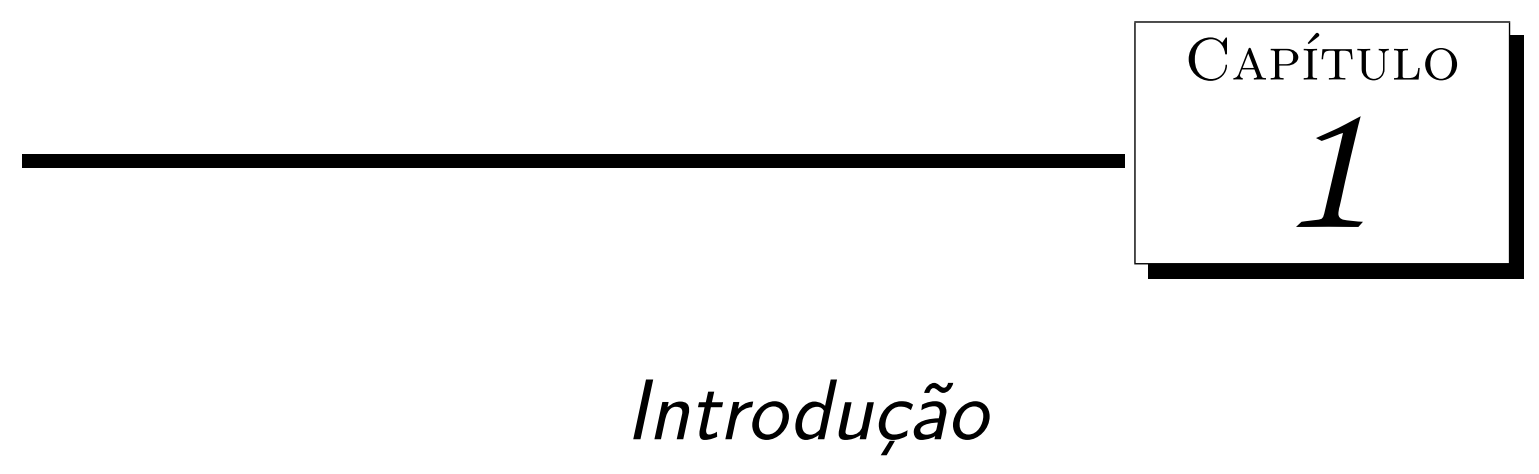

O interesse em métodos de processamento digital de imagens surgiu, principalmente, da necessidade de melhorar a qualidade da informação pictoral para a interpretação humana. Com o aumento da capacidade de processamento dos computadores e o consequente desenvolvimento de novos algoritmos para lidar com sinais bidimensionais, as imagens digitalizadas passaram a ser de uso corriqueiro nas mais diversas áreas, permitindo uma gama de aplicações cada vez maior, como por exemplo, na análise de recursos naturais, imagens de satélites e imagens biomédicas. A importância desse estudo está em melhor entender a estrutura das imagens para gerar algoritmos que realizem as tarefas com mais rapidez e eficiência.

Atualmente existem diversas técnicas de processamento de imagens baseadas em equações que descrevem fenômenos físicos, como é o caso de suavização por meio da equação do calor, edição de imagens utilizando equações de transporte e deteç̧ão de arestas por difusão anisotrópica. Tais abordagens utilizam as propriedades das imagens, em geral dadas pela escala de cores, como condições iniciais e de contorno, possibilitando que características específicas, como bordas por exemplo, possam ser preservadas durante a simulação.

Paralelamente ao desenvolvimento deste estudo abrangendo o processamento de ima- 


\section{Introdução}

gens, a simulação de fenômenos físicos realísticos tem sido uma das principais linhas de pesquisa em Computação Gráfica. O crescente interesse por tal assunto é motivado pelas aplicações na indústrias cinematográficas e de jogos interativos e, mais recentemente, na televisão digital. Na indústria de efeitos especiais, por exemplo, há uma demanda elevada para imitar convincentemente a aparência e o comportamento de fluidos tais como a fumaça, a água e o fogo. Os programas de pintura podem também beneficiar-se dos solvers de fluidos para emular técnicas tradicionais tais como a pintura de ambientes com água e óleo. A modelagem e a simulação dos líquidos são, naturalmente, de grande importância na maioria das disciplinas científicas e na engenharia. Neste contexto, simulação de escoamento de fluidos representa uma parcela importante dos problemas, uma vez que a geração de efeitos realísticos com baixo custo computacional é ainda um desafio.

A Mecânica dos Fluidos é, então, usada como a estrutura matemática padrão em que estas simulações são baseadas. Há um consenso entre os cientistas de que as equações de Navier-Stokes são um modelo muito bom para modelar o comportamento de fluidos em movimento. Milhares de livros e artigos foram publicados em várias áreas com diversas técnicas e abordagens de como calcular numericamente a solução destas equações. Qual solver usar depende, na prática, do problema a ser modelado e do poder computacional disponível. Grande parte dos problemas de engenharia requerem que a simulação forneça limites exatos nas quantidades físicas envolvidas para responder questões relacionadas à segurança, ao desempenho, etc. A aparência visual (forma) do escoamento é de importância secundária nestas aplicações. Em Computação Gráfica, por outro lado, a forma e o comportamento do líquido são de interesse preliminar, enquanto a exatidão física é secundária ou, em alguns casos, irrelevante. Os solvers de escoamentos de fluidos, para Computação Gráfica, devem idealmente fornecer ao usuário uma ferramenta que permita conseguir efeitos em tempo real. Estes fatores são mais importantes do que a exatidão física estrita, que requereria demasiado poder computacional.

O uso das equações de Navier-Stokes em processamento de imagens ainda é pouco explorada. O uso de tais equações mostra-se muito promissor, pois as equações de NavierStokes permitem que diferentes simulações possam ser realizadas ajustando apenas alguns parâmetros, o que caracteriza uma grande flexibilidade para aplicações. 


\section{Introdução}

Neste trabalho desenvolvemos um método de simulação de fluidos que atua diretamente em imagens digitais, evitando a conversão dos elementos que a compõem em entidades geométricas. De acordo com a metodologia adotada, as informações contidas na imagem são transferidas para o sistema de equações fazendo com que o escoamento passe a detectar automaticamente a presença de elementos que interferem em sua evolução.

No capítulo 2 apresentamos uma breve revisão sobre conceitos da mecânica dos fluidos e de importantes trabalhos relacionados às grandes áreas processamento de imagens e computação gráfica. Nos capítulos 3 e 4 descrevemos os métodos numéricos que compõem a base teórica para a simulação de nosso problema. Finalmente, no capítulo 5 estão disponíveis os resultados obtidos à partir da metodologia proposta. 
Introdução 


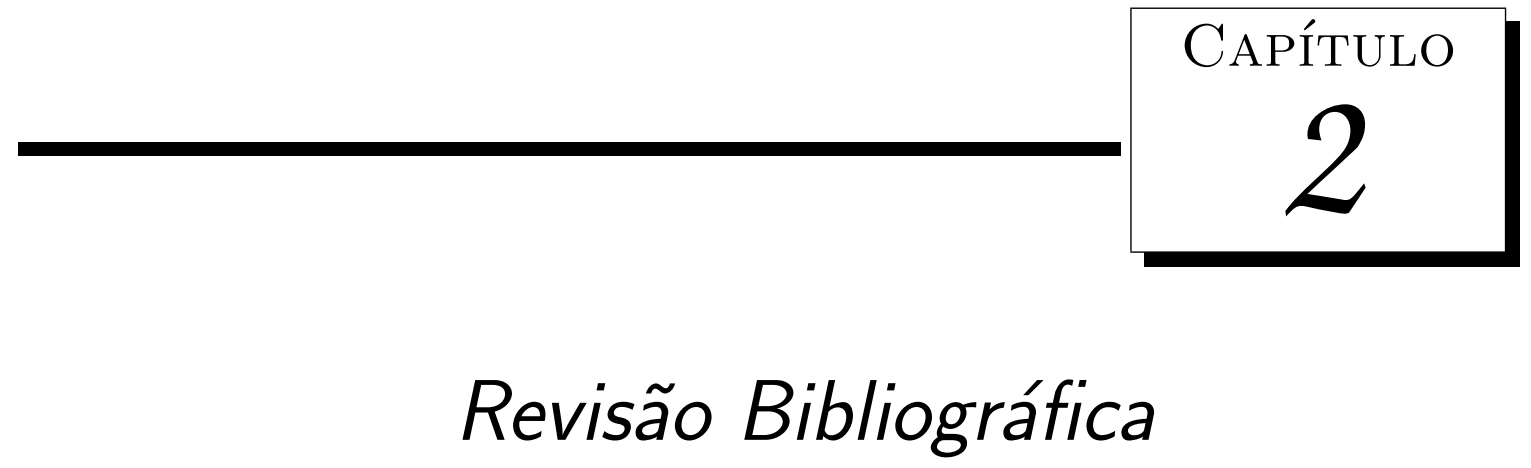

\subsection{Preliminares}

\subsubsection{EDP's e processamento de imagens}

O estudo das equações diferenciais inicia-se com a criação do cálculo diferencial e integral no século XVII. A motivação inicial para o seu estudo veio de aplicações em mecânica das partículas. Empenhados nestas aplicações, alguns físicos e matemáticos da época formulavam matematicamente fenômenos físicos, obtendo modelos matemáticos que serviam de aproximação para objetos reais em estudo. Respeitando as condições do problema formulado buscava-se então verificar a existência e unicidade de soluções para o mesmo. Naquele período, novos recursos de Análise eram exigidos podendo conduzir a novos problemas matemáticos. Após verificada a validade da solução, essa devia ser interpretada fisicamente.

Uma equação diferencial parcial (EDP) é uma equação envolvendo duas ou mais variáveis independentes $x, y, z, t, \ldots$ e derivadas parciais de uma função (variável dependente) $u=u(x, y, z, t, \ldots)$. Simbolicamente, uma EDP em $n$ variáveis independentes 


\section{Revisão Bibliográfica}

$x_{1}, \ldots, x_{n}$ é uma equação da forma

$$
F\left(x_{1}, \ldots, x_{n}, u, \frac{\partial u}{\partial x_{1}}, \ldots, \frac{\partial u}{\partial x_{n}}, \ldots, \frac{\partial^{2} u}{\partial x_{1} \partial x_{n}}, \ldots, \frac{\partial^{k} u}{\partial x_{n}^{k}}\right)=0
$$

onde $\left(x_{1}, \ldots, x_{n}\right) \in \Omega, \Omega$ subconjunto aberto de $\mathbb{R}^{n}, F$ é uma função dada e $u=u\left(x_{1}, \ldots, x_{n}\right)$ é uma função que queremos determinar, ou seja, a solução da equação.

A ordem de uma EDP é definida como sendo a ordem da mais alta derivada parcial presente em (2.1). Ela é dita linear se $F$ é algebricamente linear nas variáveis $u, \frac{\partial u}{\partial x_{1}}, \ldots, \frac{\partial u}{\partial x_{n}}, \ldots, \frac{\partial^{2} u}{\partial x_{1} \partial x_{n}}, \ldots$ e os coeficientes das variáveis são funções apenas de variáveis independentes. Caso contrário, tal EDP é chamada não-linear.

Uma imagem com dimensões $n \times m$, no sentido considerado neste trabalho, é uma matriz bi-dimensional $I=I\left(x_{i}, y_{j}\right), i=0, \ldots, n-1, j=0, \ldots, m-1$, cujos elementos indicam a intensidade do ponto relativo a sua posição. Numa imagem monocromática esta intensidade indica a luminância naquele ponto. O caso colorido é totalmente análogo considerando-se não uma, mas três matrizes de mesmas dimensões cujas intensidades correspondem, respectivamente, às componentes vermelha $(R)$, verde $(G)$ e azul $(B)$ que sobrepostas originam a cor de cada ponto representado. Os pontos da imagem, denominados pixels, em seu conjunto formam a imagem representada que, em geral, trata-se apenas de uma representação discreta de uma realidade contínua.

O uso de EDP's em processamento de imagens passou por um grande crescimento nos últimos anos. A idéia básica consiste em deformar uma imagem, uma curva ou superfície com uma EDP visando a obtenção de determinados resultados por intermédio de aproximações para a solução desta equação. Esta teoria teve início com a formulação proposta por Marr e Hildreth [18] em 1980, cuja metodologia envolveu o uso de uma equação diferencial conhecida como a equação do calor.

Umas das principais vantagens da utilização de EDP's na análise de imagens está na consideração de um domínio contínuo, simplificando o formalismo do modelo, que torna-se independente da malha utilizada no problema discreto. Assim sendo, uma imagem pode ser definida como sendo uma função intensidade definida em cada ponto do domínio de trabalho. 


\subsubsection{Dinâmica dos Fluidos Computacional}

A Dinâmica dos Fluidos é um ramo da ciência que envolve estudos ligados a problemas de fluidodinâmica, termodinâmica, hidráulica, entre outros. Em muitas indústrias, os produtos estão relacionados diretamente com a Dinâmica dos Fluidos e se investe grandes quantidades de recursos para desenvolver novas tecnologias na área de Dinâmica dos Fluidos Computacional e Experimental. Contudo o investimento para a obtenção de resultados experimentais é muito dispendioso, e, devido a isto, vem se investindo muito em modelagem matemática e simulação numérica para obtenção destes resultados, sendo chamado este método de Dinâmica dos Fluidos Computacional (DFC). Esta metodologia tem baixo custo e apresenta resultados muito satisfatórios.

O impulso inicial surgiu à partir do ano de 1822, após Claude-Louis Navier e George Gabriel Stokes desenvolverem um conjunto de equações que descrevem o movimento das substâncias fluidas, tais como líquidos e gases. Antes de enunciar tais equações, vamos apresentar alguns conceitos básicos à cerca dos fluidos.

Quando a densidade de um fluido não muda ao longo de um escoamento, ou podemos desprezar qualquer alteração em seu valor, dizemos que o escoamento é incompressível. Embora nenhum fluido seja realmente incompressível, em escoamentos que não envolvam gradientes elevados de pressão, temperaturas, mudanças de concentrações ou alta velocidades, podemos considerar o fluido incompressível. Escoamentos laminares podem ser considerados como aqueles que não apresentam uma mudança brusca em sua configuração devido a presença de forças agindo no sistema. Se o escoamento não é laminar, dizemos que o mesmo é turbulento.

O escoamento laminar pode ainda ser caracterizado por aquele em que camadas muito finas (lâminas) de fluido parecem deslizar umas sobre as outras (figura 2.1). Esse movi-

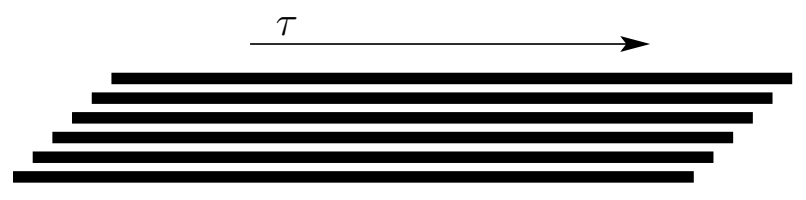

Figura 2.1: Deslizamento das lâminas de fluido. 


\section{Revisão Bibliográfica}

mento, ocasionado pela presença de uma força atuante no sistema, produz uma tensão ${ }^{1}$ de cisalhamento $\tau$ entre as camadas e tende a deformar elementos do fluido, figura 2.2.

Experimentalmente, é possível comprovar para muitos fluidos a existência de uma relação linearmente proporcional entre a tensão de cisalhamento e a taxa de deformação das lâminas de fluido. À constante de proporcionalidade própria para cada fluido, Newton deu o nome de viscosidade ${ }^{2}$ e a denotou por $\mu$. Portanto, são considerados fluidos newtonianos aqueles cuja relação tensão de cisalhamento/taxa de deformação é constante, independente da deformação e do tempo.

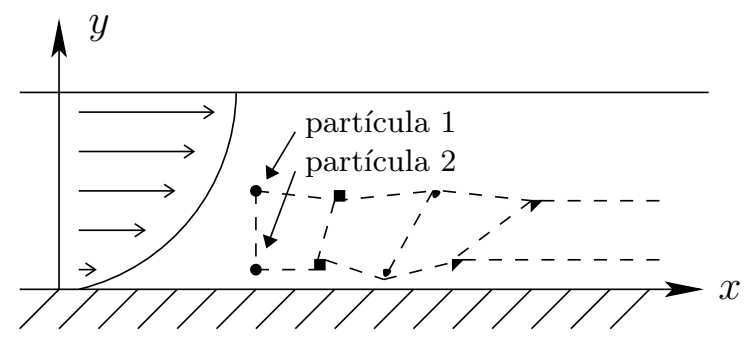

Figura 2.2: Movimento relativo de duas partículas de fluido na presença de uma tensão de cisalhamento.

As equações que governam o comportamento de um fluido em movimento são amplamente conhecidas na comunidade científica como as equações de conservação e, devido a sua complexidade, são adequadas ao tipo de escoamento em estudo, podendo ser bastante simplificadas. Considerando, por exemplo, um fluido incompressível newtoniano, as equações podem ser postas na forma vetorial

$$
\nabla \cdot \mathbf{u}=0
$$

e

$$
\frac{\partial \mathbf{u}}{\partial t}=-\frac{1}{\rho} \nabla p-(\mathbf{u} \cdot \nabla) \mathbf{u}+\nu \nabla^{2} \mathbf{u}+\mathbf{f}
$$

onde $p$ é a pressão, $\rho$ a densidade do fluido, $t$ o tempo, $\mathbf{u}$ a velocidade, $\mathbf{f}$ uma força externa agindo no sistema e $\nu=\mu / \rho$ a viscosidade cinemática do fluido. Estas são as famosas Equações de Navier-Stokes. Em (2.2-2.3), o operador · simboliza o produto escalar no

\footnotetext{
${ }^{1}$ Tensão representa o quociente entre o módulo de uma força e a área sobre a qual ela age.

${ }^{2}$ Também conhecida como viscosidade dinâmica ou molecular.
} 


\section{Revisão Bibliográfica}

espaço bidimensional. O divergente de uma função diferenciável $\varrho$ é dado por $\nabla \cdot \varrho$, sendo portanto o operador $\nabla$, em coordenadas cartesianas bidimensionais, dado por

$$
\nabla=\mathbf{i} \frac{\partial}{\partial x}+\mathbf{j} \frac{\partial}{\partial y}
$$

onde $\mathbf{i}$ e $\mathbf{j}$ são os vetores unitários nas direções $x$ e $y$, respectivamente. O operador laplaciano no espaço euclidiano bidimensional é definido como o divergente do gradiente, $\nabla^{2}=\nabla \cdot \nabla$ ou, equivalentemente, a soma das derivadas parciais de segunda ordem em relação as variáveis espaciais

$$
\nabla^{2}=\mathbf{i} \frac{\partial^{2}}{\partial x^{2}}+\mathbf{j} \frac{\partial^{2}}{\partial y^{2}}
$$

As equações (2.2-2.3) representam expressões matemáticas de princípios físicos bem familiares. A equação (2.2) é conhecida como equação da continuidade ou equação de conservação de massa e expressa o equilíbrio entre a variação temporal da quantidade de massa no elemento e a vazão líquida de massa através das fronteiras do elemento. O princípio de conservação de massa estabelece que na ausência de fontes ou sorvedouros de massa, toda a massa que entra em um sistema deve sair e/ou se acumular no mesmo [11]. A equação (2.3) é conhecida como equação de conservação de movimento, obtida à partir da segunda lei de Newton, e afirma que a taxa de variação temporal da quantidade de movimento de uma partícula é igual a resultante das forças que agem sobre essa partícula $[11]$.

Diferentemente das equações algébricas, estas equações não procuram estabelecer uma relação entre as variáveis de interesse (por exemplo, velocidade e pressão), e sim, estabelecer relações entre as taxas de variação ou fluxos destas quantidades. Em termos matemáticos, estas razões correspondem a suas derivadas.

Os modelos matemáticos obtidos por meio destas equações dificilmente possuem solução analítica. Dessa forma, precisam ser discretizados para a realização de simulações numéricas. O resultado desta discretização é a substituição do meio contínuo inicial do modelo por um conjunto discreto e finito de pontos no espaço e no tempo, nos quais as derivadas que aparecem nas equações serão aproximadas. Duas abordagens podem ser adotadas para formular as versões discretas das equações do modelo: a Euleriana e a 


\section{Revisão Bibliográfica}

Lagrangeana. A abordagem Euleriana pode ser exemplificada pelos métodos tradicionais, onde o conjunto de pontos da malha é conectado seguindo uma topologia conveniente. A abordagem Lagrangeana é independente de malhas. Neste caso, no lugar das malhas, são utilizadas partículas para formulação das versões discretas dos modelos. Combinações dessas duas abordagens também podem ser consideradas.

\subsection{Fluidos em Computação Gráfica}

Há mais de duas décadas, técnicas de simulação de fluido com propósitos específicos vem sendo desenvolvidas no campo da Computação Gráfica. Nesta seção apresentamos alguns dos trabalhos mais relevantes, que contribuíram para significativos avanços nesta área.

A maneira mais natural de modelar fluidos consiste do uso das equações físicas que descrevem seus movimentos. Uma vez as equações governantes são conhecidas e existe tecnologia de hardware para resolvê-las numericamente, uma grande quantidade de métodos têm sido propostos na literatura de DFC para simular o comportamento de fluidos. Consistem de técnicas geralmente complexas e computacionalmente intensivas e não prontamente adaptáveis ao que poderia ser considerado as exigências básicas de um sistema de animação de computador. Uma das dificuldades encontradas quando da utilização desses métodos para animação caracteriza o custo da simulação e seu controle. Animações baseadas na Física normalmente confiam à simulação numérica direta o alcance de realismo. Em termos de engenharia, isto significa que condições iniciais e de contorno são especificadas e o processo se dá livremente com influência secundária apenas por parte do programador. Nesta seção vamos apresentar alguns dos trabalhos mais relevantes no contexto da DFC contribuíram para avanços consideráveis

Um dos principais problemas estudados na área é o desenvolvimento de métodos numéricos para obtenção, com a maior exatidão possível, da solução do conjunto de equações estabelecido. Existem diversos métodos com essa finalidade que se distinguem, essencialmente, pela forma de aproximar as derivadas presentes nas equações e o uso ou não de malhas convenientemente adaptadas ao problema.

Em diversas aplicações, como no caso da simulação do ar em torno de aviões, durante 


\section{Revisão Bibliográfica}

preenchimento de moldes com geometrias complexas, ou em situações em que se deseja refinamento local, o uso de malhas cartesianas, comumente empregadas em Métodos de Diferenças Finitas, torna-se bastante complicado. Nesses casos, o uso de malhas nãoestruturadas se justifica pela facilidade de adaptação destas malhas em geometrias complexas, permitindo que refinamentos locais possam ser feitos em regiões específicas. Para a Mecânica dos Fluidos Computacional, revelam-se bastante promissores os métodos que possuem maior versatilidade geométrica e que utilizam técnicas de balanço de conservação das propriedades no volume de controle, como o método de volumes finitos e também o método de elementos finitos que consiste na discretização de um meio contínuo em pequenos elementos, mantendo as mesmas propriedades do meio original. Esses elementos são descritos por equações diferenciais e resolvidos por modelos matemáticos, para que sejam obtidos os resultados desejados. Ambos os métodos de volumes finitos e de elementos finitos, apesar de poderem ser aplicados a malhas cartesianas, são comumente aplicados em malhas não-estruturadas triangulares e/ou híbridas.

Um dos problemas mais abordados por pesquisadores da comunidade de Computação Gráfica consiste na modelagem do fenômeno de escoamento de fluido, onde uma representação consistente do modelo da superfície livre, que pode interagir com outros fluidos presentes em um sistema, é almejado. Tais trabalhos utilizam desde métodos de Fourier a representações paramétricas da superfície do fluido. Alguns deles destacam-se pela maneira que tentam modelar realisticamente o comportamento de ondas, incluindo mudanças em seu comportamento como função da profundidade da água.

A computação numérica de escoamentos com interface móvel é mais trabalhosa, por exemplo, nos casos em que a interface separa fluidos de diferentes densidades, tais como água e óleo, ou água e ar.

Escoamentos multifásicos estão presentes em importantes processos no meio natural e nas diversas áreas tecnológicas. O entendimento das propriedades destes processos em larga escala se dá através do estudo da evolução de partículas existentes no escoamento. Quando economicamente viável, a realização de experimentos dificilmente determina com exatidão a dinâmica destas partículas. Surgindo como alternativa, simulações numéricas oferecem a oportunidade da análise detalhada do escoamento. Tais simulações numéricas, 


\section{Revisão Bibliográfica}

onde estão incluídos o devido cálculo de forças inerciais, viscosas e de tensões interfaciais, além de obedecerem ao movimento de interfaces deformáveis entre as diferentes fases, caracterizam um dos problemas mais abordados na Dinâmica dos Fluidos Computacional.

Osher e Sethian [23] apresentaram em 1988 um trabalho que resultou em uma significativa contribuição para a comunidade científica. Nele, introduziram a formulação level set para modelagem de interfaces entre fluidos presentes em um sistema. A técnica consiste em representar a interface por um conjunto de nível de uma função suave, levando a fórmulas convenientes para o cálculo da curvatura da interface requerida na implementação da tensão superficial [29].

Utilizando a formulação proposta por Osher e Sethian [23], Sussman et al. [32] desenvolveram um algoritmo baseado em uma discretização de segunda ordem para aproximação da interface em um escoamento incompressível abrangendo duas fases. O procedimento para atualização da velocidade e da pressão foi implementado à partir de um método de projeção, com adaptação de um esquema de diferenças avançado para tratamento dos termos convectivos da equação de Navier-Stokes. Dessa forma, evitaram a ocorrência de uma excessiva difusão numérica, muito prejudicial ao tratamento da interface, que é mantida durante todo o processo iterativo sem necessidade de ser reconstruída. Os experimentos de Sussman et al. [32] simularam o escoamento de bolhas de ar e gotas de água, conforme ilustram as figuras 2.3 e 2.4.

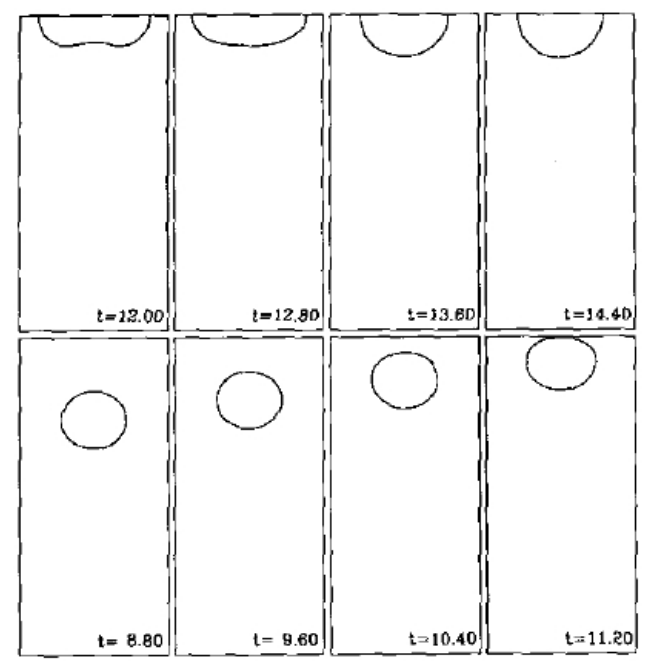

Figura 2.3: Evolução de uma bolha de ar com alta tensão superficial em diferentes passos de tempo [32]. 


\section{Revisão Bibliográfica}

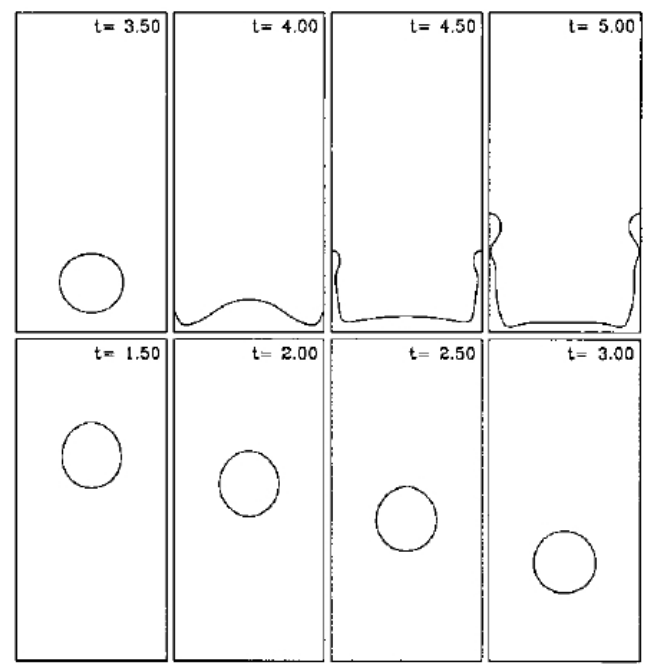

Figura 2.4: Evolução de uma gota de água com tensão superficial em diferentes passos de tempo [32].

Em uma publicação posterior, Sussman et al. [31] aperfeiçoaram seu esquema Euleriano, melhorando a precisão e eficiência do algoritmo.

Pesquisadores como Rasmussen, Nguyen, Geiger and Fedkiw [26] têm focado seus estudos na simulação de fenômenos naturais em larga escala, como por exemplo, a simulação de uma explosão nuclear, uma vez que é muito difícil recuperar níveis de detalhes necessários, por exemplo, em um filme. Eles simularam esses fenômenos a partir do movimento de partículas segundo a dinâmica de fluidos gerada por um campo de velocidades. A idéia básica é combinar resultados de simulações $2 \mathrm{D}$ de alta resolução com um campo de velocidade 3D de Kolmogorov, que é algumas ordens de magnitude mais eficiente que os cálculos 3D de escoamentos de fluidos. Segundo os autores, esta metodologia permite controlar campos em 2D uma vez que os resultados podem ser obtidos em tempo real/interativo, e apresenta a vantagem de poder criar uma biblioteca completa de simulações $2 \mathrm{D}$, sendo possível facilitar a escolha do ponto de partida para futuras animações. A Figura 2.5 ilustra alguns resultados obtidos pelos autores.

Guendelman et al. [13] apresentaram recentemente um método para o acoplamento de sólidos e fluidos que pode tratar sólidos finos, modelados por uma superfície triangulada. Como os algoritmos clássicos de acoplamento de sólidos/fluidos consideram o objeto sólido dentro da malha do fluido, uma abordagem nova foi necessária para tratar os objetos finos que não contêm região interior. Além disso, propuseram técnica para reforçar 


\section{Revisão Bibliográfica}
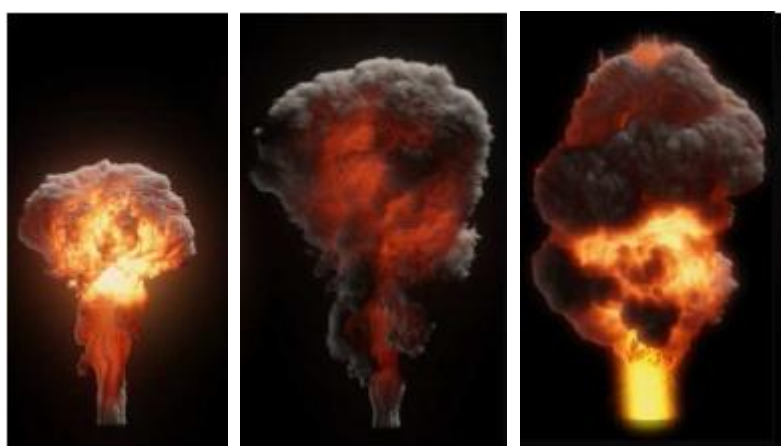

Figura 2.5: As chamas das explosões das imagens à esquerda e ao centro foram geradas pela técnica 2D de Rasmussen et al. [26], enquanto a chama à direita foi gerada por uma simulação completa 3D [26].

corretamente a incompressibilidade, de modo que o líquido não comprima incorretamente (e aparente estar perdendo massa) perto da superfície triangulada. Isto permite a interação robusta de tecidos e shells com água. O método proposto trabalha para ambos os casos de corpos rígidos e variedades deformáveis, como tecidos. Os exemplos ilustrado na Figura 2.6 demonstram a boa performance do método, produto de uma boa adaptação entre o método particle level set para tratar a relação água/ar e método recentemente proposto para tratar a relação sólido/fluido. Eles implementaram o método usando octrees uniformes e adaptativas.
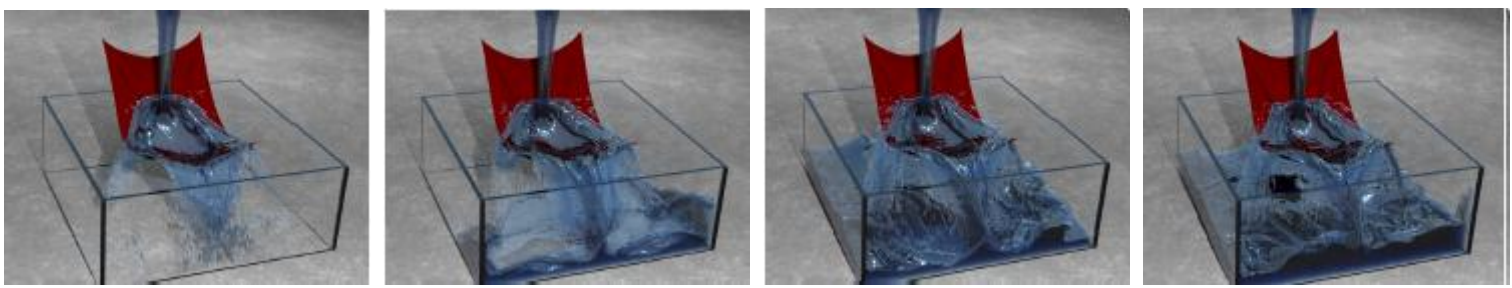

Figura 2.6: Queda de água sobre um tecido preso pelas quatro extremidades [13].

Muller et al. [21] apresentaram um método para simular a interação de fluidos com sólidos deformáveis. O método é projetado para o uso em sistemas interativos tais como os simuladores virtuais de cirurgias, onde a interação entre os líquidos e o tecido em tempo real é importante. Na computação gráfica, uma variedade de técnicas foram propostas para modelar fluidos e objetos deformáveis de forma interativa. Tão importante quanto uma animação aceitável é a rápida e estável modelagem de suas interações. O método descrito por Muller et al. [21] modela a troca de quantidade de movimento entre modelos de fluidos baseado em partículas Lagrangeanas e os sólidos representados por uma malha poligonal, simulando repulsão, adesão e fricção próximos à interface sólido-líquido. Para 


\section{Revisão Bibliográfica}

modelar a interação sólido-fluido eles utilizaram partículas de contorno virtuais. Alguns dos resultados obtidos são ilustrados na figura 2.7.
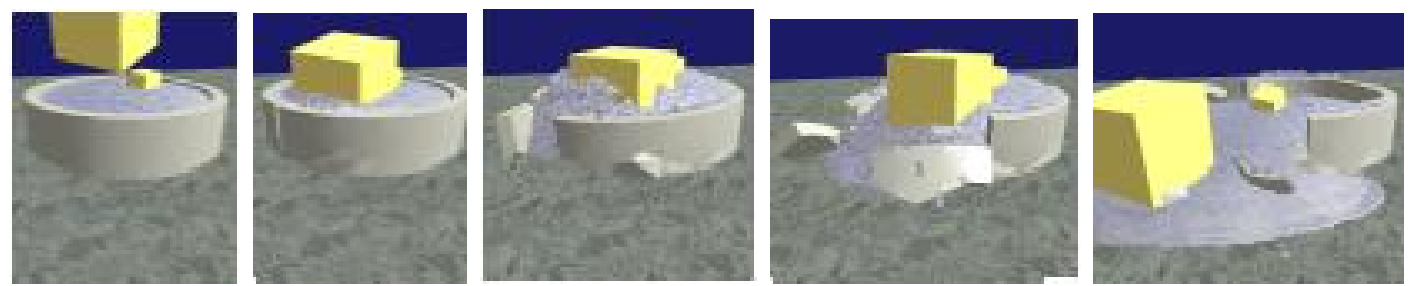

Figura 2.7: Uma caixa cai em uma piscina e gera ondas de choque que causam uma fratura na mesma [21].

Em outro trabalho, Muller et al. [22] propõem uma técnica nova para modelar a interação fluido/fluido através do método Smoothed Particle Hydrodynamics (SPH). Para a simulação da interação ar/água, as partículas de ar são geradas no decorrer da simulação, e somente onde são necessárias. Eles modelaram também mudanças de fase e forças superficiais. Segundo eles, contrariamente ao que ocorre nas simulações Eulerianas, as partículas são particularmente adequadas para modelar a interação de tipos diferentes de fluidos e de mudanças de fase, pois podem ser geradas ou destruídas dinamicamente, permitindo representar o ar em determinado ambiente somente onde é necessário. Eles depararamse com o problema da limitação da aproximação SPH para partículas isoladas ou mal amostradas, e então propuseram uma técnica para contornar tal problema. Segundo os autores possivelmente existem outras maneiras de contornar determinado problema, e este estudo voltado para sua resolução seria, naturalmente, objeto de trabalhos futuros. Alguns dos resultados obtidos segundo a abordagem de Muller et al [22] são ilustrados na figura 2.8 .
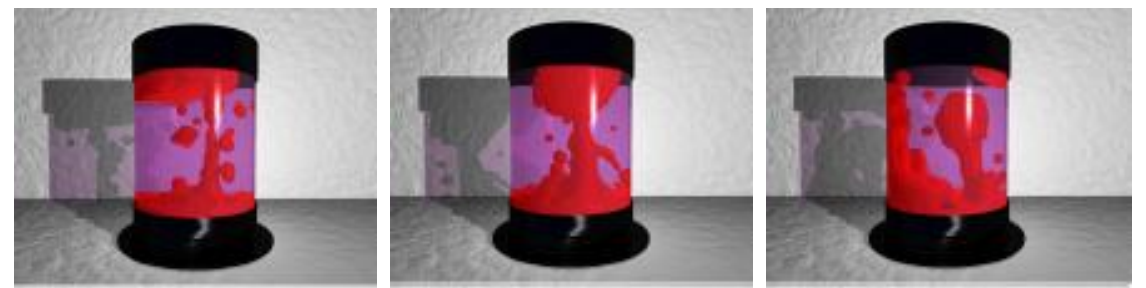

Figura 2.8: As técnicas apresentadas neste trabalho permitem a simulação de uma lâmpada de lava. Os efeitos interessantes dentro da lâmpada são causados por forças da tensão superficial entre fluidos de diferentes polaridade e difusão de temperatura [22]. 


\section{Revisão Bibliográfica}

\subsection{Fluidos em Imagens}

A modificação de uma imagem de maneira indetectável por aqueles que não conhecem a imagem original é uma prática tão antiga quanto as primeiras criações artísticas relacionadas a pintura. Devido a deterioração ocorrida com o tempo e outras circunstâncias, artesãos especializados eram os responsáveis pela reconstrução legível de porções perdidas ou danificadas das obras, restaurando sua integridade. Ao processo de automatização relacionado à tarefa do artesão no trabalho de repintura de imagens dá-se o nome de retoque digital.

A idéia do retoque digital é efetuar modificações e/ou correções em uma imagem, gerando como resultado uma imagem harmoniosa e dentre seus objetivos podemos citar a restauração de imagens danificadas, desopilação de objetos, remoção de textos superpostos e a geração de efeitos especiais.

Bertalmio et al. [3] desenvolveram um algoritmo para restauração digital de imagens e remoção de objetos que, em síntese, reproduz a idéia básica utilizada por restauradores profissionais. Após o usuário selecionar a região $D$ a ser restaurada, sem restrições em sua topologia, o algoritmo automaticamente a preenche com informações disponíveis em sua vizinhança $\delta D$ (figura 2.9 ).
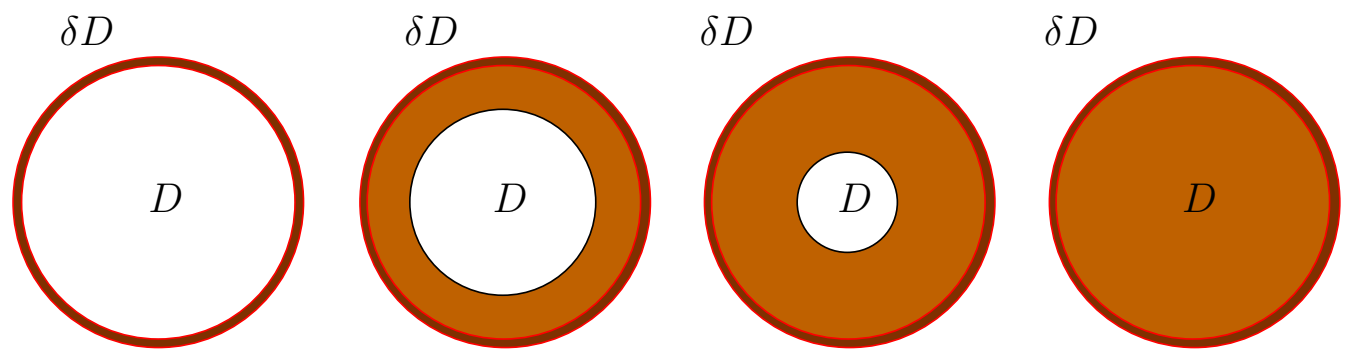

Figura 2.9: Transporte de informação em direção ao interior de $D$.

Para a discretização do problema, Bertalmio e Sapiro utilizaram esquemas de diferenças. Durante o processo iterativo, a imagem original entra em loops de retoque, sendo que somente os pixels contidos na região $D$ são modificados. Intercalado a alguns desses loops, uma iteração de difusão anisotrópica é executado. O processo é repetido até a obtenção de uma imagem otimizada. 


\section{Revisão Bibliográfica}

Imagens coloridas são consideradas como um conjunto de três imagens. Para cada uma delas a técnica descrita é aplicada independentemente.
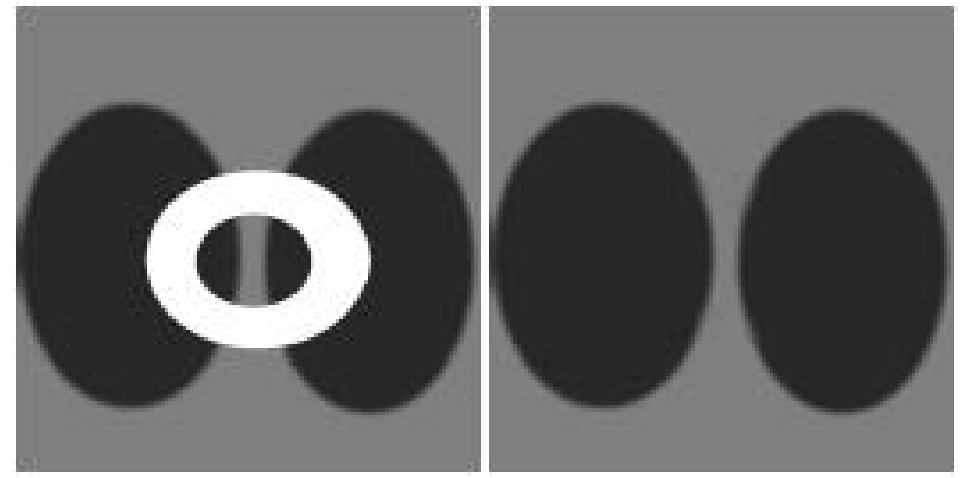

Figura 2.10: Imagem sintética original e imagem retocada, respectivamente [3].

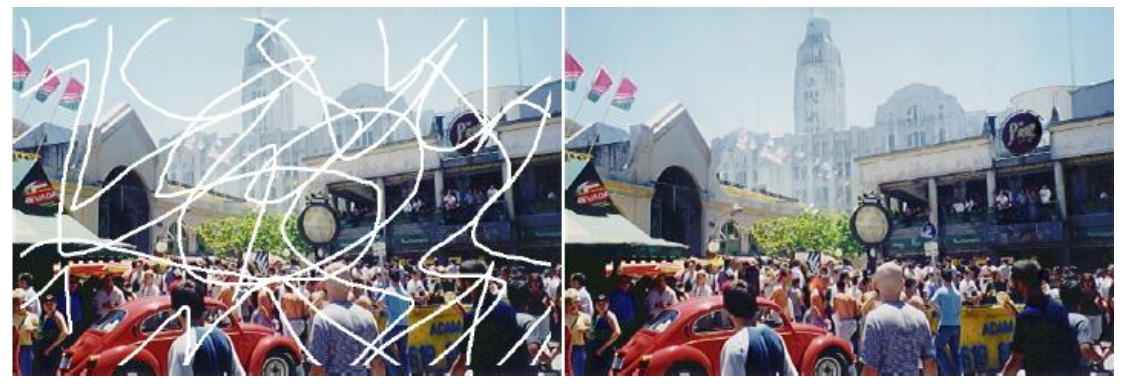

Figura 2.11: Restauração de uma imagem colorida com remoção de elementos gráficos superpostos [3].

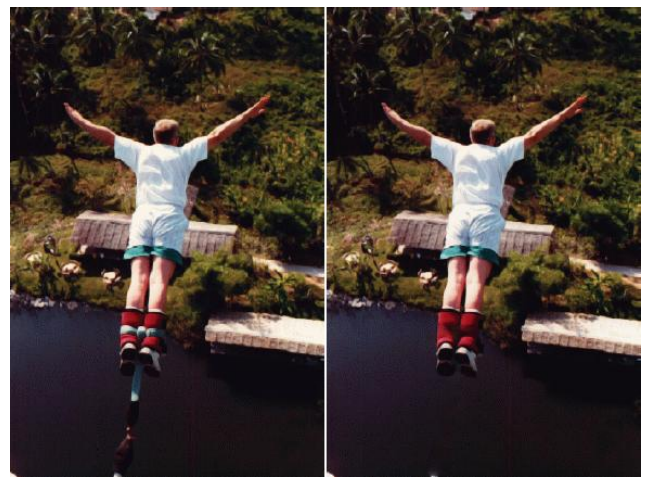

Figura 2.12: Remoção de uma corda presa aos pés de um esportista [3].

A figura 2.10 mostra uma imagem sintética com a região a ser retocada e a imagem final resultante do processo iterativo. A figura 2.11 apresenta uma imagem colorida degradada e sua restauração. Finalmente, a figura 2.12 ilustra a remoção de um objeto da imagem, neste caso a corda presa aos pés do esportista. 


\section{Revisão Bibliográfica}

Em um trabalho posterior, Bertalmio et al. [2] elaboraram um método baseado nas equações de Navier-Stokes (2.2-2.3) cuja idéia principal consiste no tratamento da imagem como uma função corrente para um escoamento incompressível. Apesar de o trabalho com as variáveis primitivas não estar descartado, os autores utilizaram a formulação correntevorticidade $^{3}$. O algoritmo envolve a solução direta das equações (2.2-2.3) para um fluido incompressível, utilizando de idéias da dinâmica dos fluidos para propagar informações continuamente do exterior para a região de interesse.
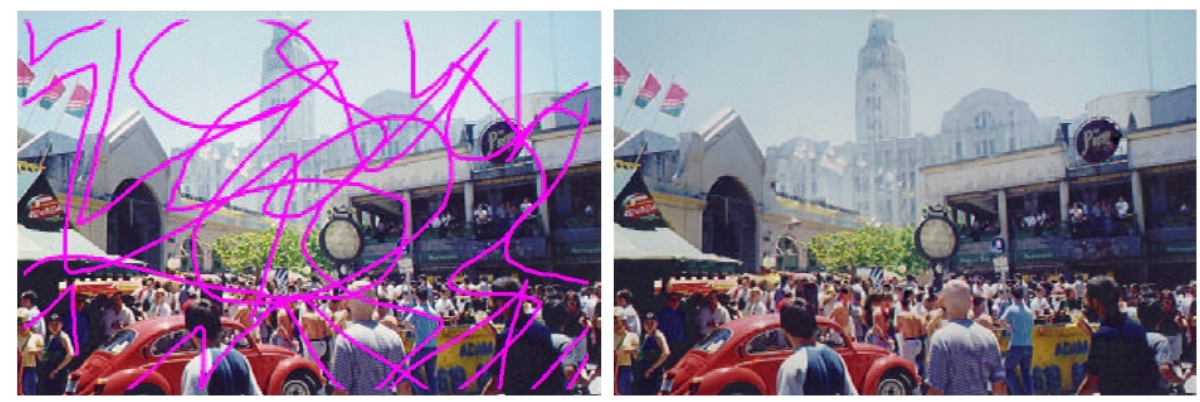

Figura 2.13: Restauração de uma imagem colorida com remoção de elementos gráficos superpostos via equações de Navier-Stokes[2].
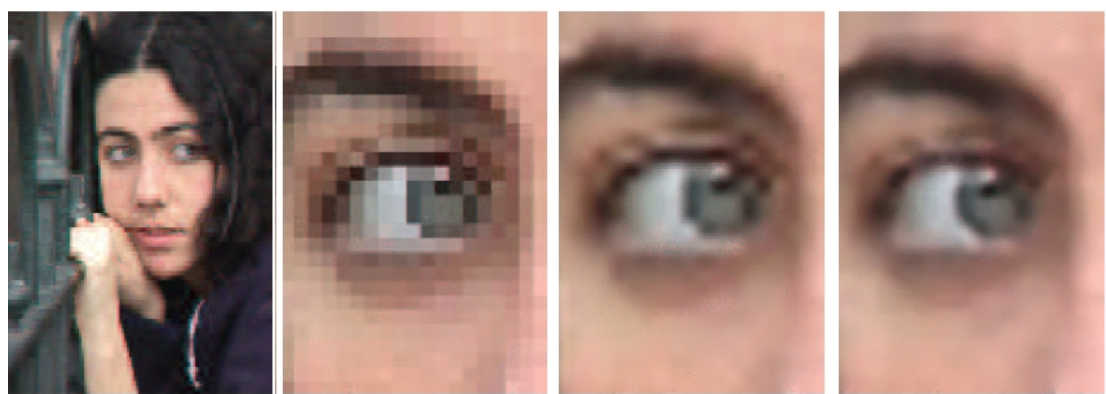

Figura 2.14: Da esquerda para a direita: imagem original, olho esquerdo ampliado em 9 vezes (de $19 \times 27$ pixels para $169 \times 241$ pixels) com uma interpolação de ordem zero (replicação), interpolação bicúbica e aplicação do método proposto[2].

A principal analogia construída pelos autores foi o paralelo entre a função corrente em um fluido incompressível bidimensional e o papel da função imagem $I$ no método de retoque digital descrito em [3], permitindo o desenvolvimento de um novo método que alcança equações semelhantes ao anterior.

\footnotetext{
${ }^{3} \mathrm{~A}$ formulação corrente-vorticidade tem como objetivo principal evitar o cálculo da pressão pela sua eliminação das equações de momento.
} 


\section{Revisão Bibliográfica}

As figuras 2.13 e 2.14 representam alguns dos resultados obtidos. À primeira delas, o algoritmo foi aplicado para a remoção de elementos gráficos indesejáveis na imagem. Observamos a equivalência entre essa e a imagem da figura 2.11. À segunda, o algoritmo é aplicado apenas à componente de brilho da imagem e realiza um processo de suavização na mesma.

Atualmente, na área médica, técnicas de processamento de imagens aliadas a teoria da dinâmica dos fluidos buscam simular o complexo escoamento em passagens vasculares, como nas artérias cerebral e carótida. Com os avanços obtidos, os profissonais responsáveis podem obter informações necessárias para identificar patologias, o modo como evoluem e formas eficientes de tratamento. O grande problema está concentrado na extração da superfície de interesse e em sua conversão a um domínio computacional apropriado para um solver de escoamento de fluidos.
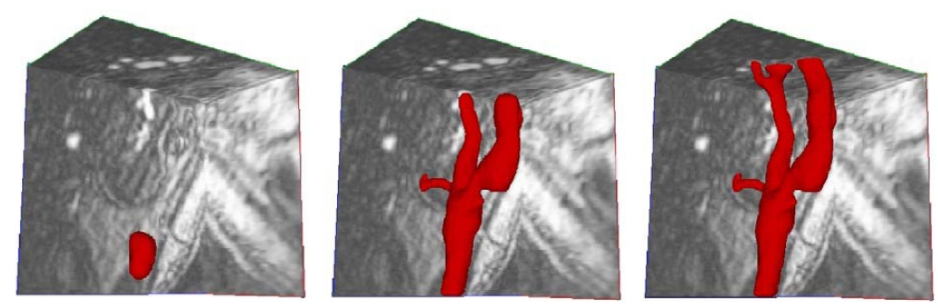

Figura 2.15: Três tempos sucessivos da segmentação da artéria carótida [10].

Deschamps et al. [10] apresentaram um método para simulação de um escoamento sanguíneo em uma geometria arterial realística. Métodos do tipo fast-marching e level-sets [27] foram utilizados para a extração da superfície, figura 2.15. Tais métodos numéricos possibilitam o acompanhamento da evolução de contornos e superfícies e, quando acoplados, apresentam bons resultados em um tempo muito curto se comparado a outras técnicas de segmentação. Para a simulação do fluido, figura 2.16, fizeram uso de algumas bibliotecas computacionais do software Chombo [6], que fornecem uma estrutura para gerenciamento de dados, operadores numéricos e solvers lineares necessários a uma formulação baseada no método da fronteira imersa, este utilizado durante a construção da malha computacional. Algumas adaptações foram realizadas e implementadas, gerando uma formulação inspirada nas equações de Navier-Stokes (2.2-2.3) com condições de contorno do tipo Dirichlet e estabilidade agregada apenas a condição CFL para o termo convectivo 


\section{Revisão Bibliográfica}

das equações.

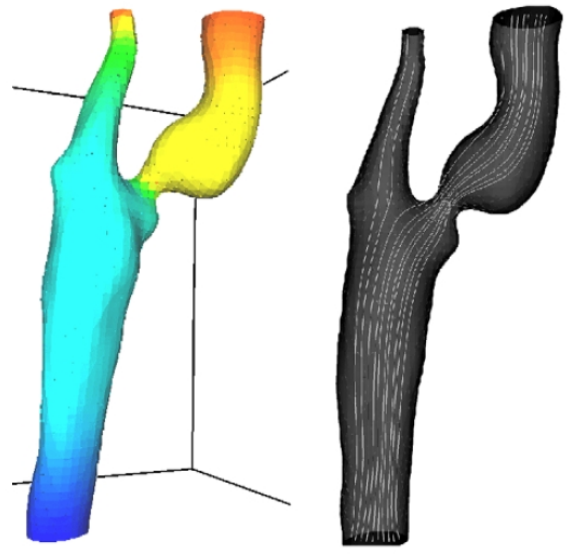

Figura 2.16: Simulação do escoamento sanguíneo na artéria carótida. À esquerda: pressão na superfície. À direita: linhas de fluxo acompanhando o escoamento [10].

Dentre alguns dos bons resultados obtidos por Deschamps et al. [10], destaca-se o rápido e automatizado processo de obtenção da malha computacional à partir da segmentação inicial sem perda de informações importantes da geometria do objeto manipulado.

Sistemas de pintura que capturam a complexidade, variedade e riqueza de pinturas artísticas somente aparecem recentemente na literatura. As técnicas existentes podem ser classificadas em três abordagens distintas. A primeira delas trabalha diretamente à partir de malhas ou outras geometrias bi e tridimensionais. A segunda abordagem têm como fonte fotografias ou imagens de entrada que são devidamente exploradas. Por último, abordagens baseadas em sistemas interativos dependem de uma uma entrada previamente definida pelo usuário.

Em 1991, Cockshott [5] identificou o problema principal da definição de sistemas de pintura como sendo a falta de brilho nas imagens por eles produzidas quando comparadas às feitas por métodos tradicionais. De acordo com Cockshott, isto ocorre devido ao shallowness dos modelos de pintura, bem como a falta de compreensão do processo de pintura real e o comportamento das tintas. Seu modelo, baseado em um autômato celular, inclui regras de tratamento para a tensão superficial, gravidade e difusão das propriedades. No mesmo ano, Small [28] introduz um modelo para pintura à base de água também baseado no princípio de autômato celular. 


\section{Revisão Bibliográfica}

Curtis et al. [9] apresentaram um modelo sofisticado em um artigo de 1997. Nele incorporou as equações de Navier-Stokes (2.2-2.3) visando a simulação da criação de imagens pintadas à base de água. O esquema de pintura consiste de um conjunto ordenado de esmaltes translúcidos que são individualmente renderizados e definidos usando as equações de Kubelka-Munk [15] para a obtenção da imagem final. O modelo proposto é capaz de simular uma vasta gama de efeitos de pintura. Um exemplo de pintura a base de água é mostrado na figura 2.17. O escoamento de fluidos e a dispersão de pigmentação também

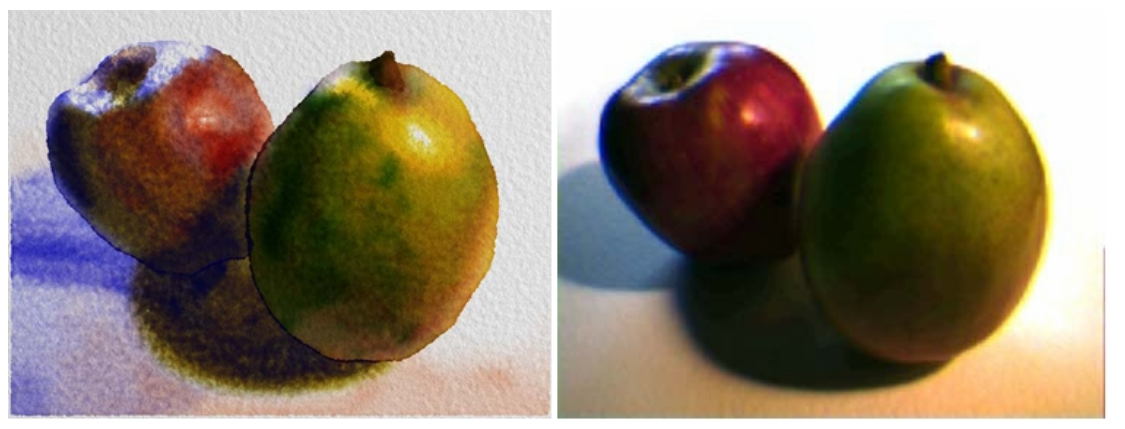

Figura 2.17: À esquerda: obtenção automática de uma coloração à base de água. À direita: imagem original obtida de uma câmera digital de baixa resolução [9].

é realizada por meio de um autômato celular.

Baxter et al. [1] foram os primeiros a apresentar uma simulação de pintura interativa baseada nas equações governantes dos fluidos que capturam uma enorme variedade de estilos similares a óleo e acrílico. O modelo inclui a simulação numérica para recriar a a física do fluido de tinta e um aparato óptico otimizado para imitar de maneira convincente a aparência da pintura em seu estado final. Este modelo acabou dando origem a um software especializado denominado IMPaSTo. A figura 2.18 apresenta um resultado obtido pelo software.

Van Laerhoven e Van Reeth [16] desenvolveram um método para simular em tempo real a pintura a base de água, sendo capaz de capturar diversos efeitos da natureza desta arte. Um protótipo foi implementado em hardware gráfico e o processo interativo foi positivamente avaliado por diversos profissionais da área, uma vez que a interação entre o usuário e o processo de renderização deixaram de ocorrer em estágios separados, o que acarretava em uma discordância entre o que o sistema devolveu e o que realmente o artista tinha em mente. 


\section{Revisão Bibliográfica}

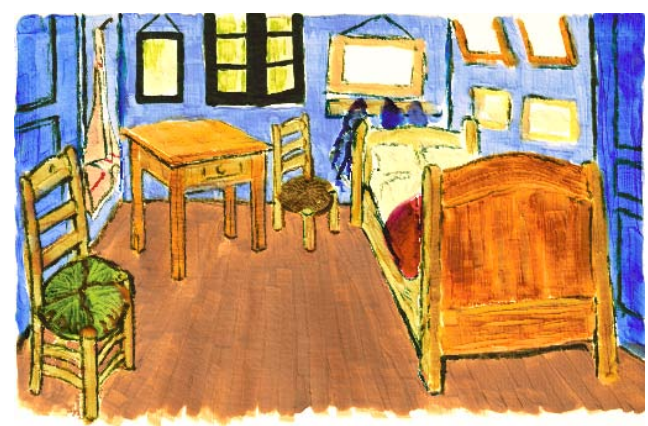

Figura 2.18: Uma pintura criada com IMPaSTo adaptada de Vincent Van Gogh [1].
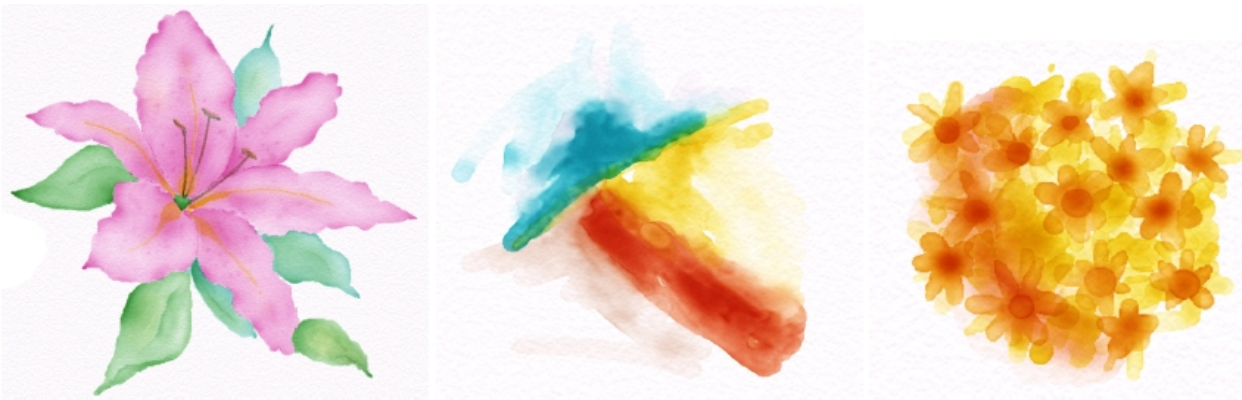

Figura 2.19: Exemplos de pinturas geradas pelo método proposto [16].

Para reproduzir a complexidade, variedade e riqueza de configuração das obras resultantes, exploraram a capacidade de processamento de um hardware gráfico para a simulação do escoamento da água na pintura, baseada na equação (2.3), e renderização por intermédio de uma implementação interativa do modelo de reflectância de KubelkaMunk [15]. A figura 2.19 apresenta alguns exemplos de imagens geradas pelo método proposto. 


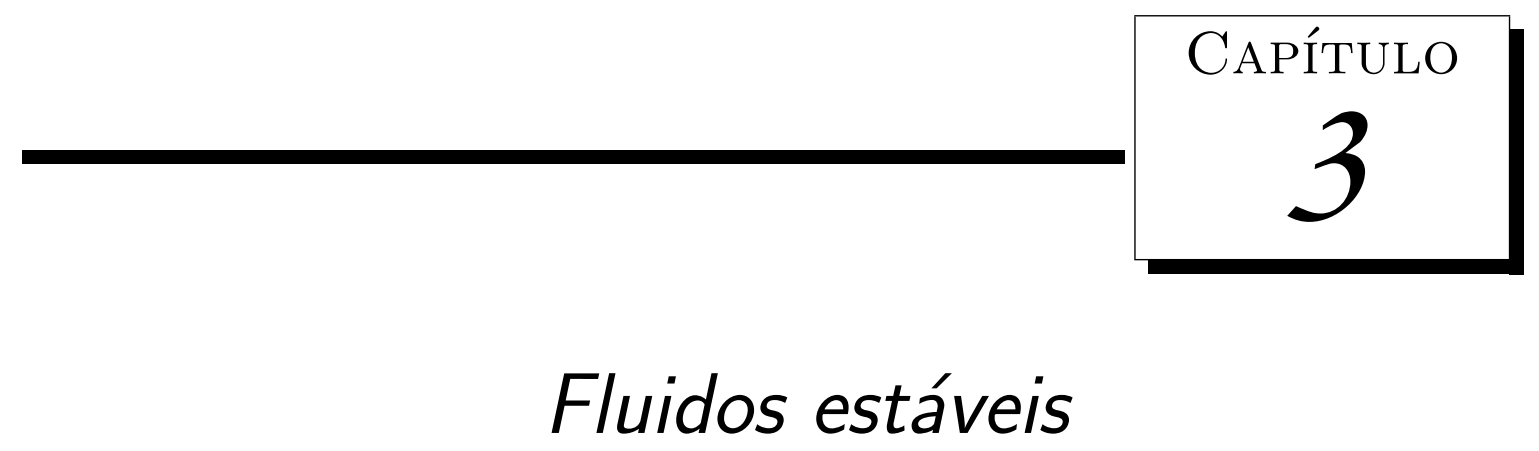

Em 1999, Jos Stam [30] introduziu um novo e eficiente método para resolução das equações de Navier-Stokes que representou um grande avanço em termos de simulação em tempo real para Computação Gráfica. Stam apresentou um esquema semi-lagrangeano incondicionalmente estável para qualquer que seja o valor do passo no tempo entre sucessivas iterações. Para uma resolução estável do termo convectivo das equações foi adaptado o método das características e a conservação de massa é alcançada pela aplicação da decomposição de Helmholtz-Hodge ao campo de velocidades resultante. Neste capítulo, uma breve descrição do trabalho de Stam[30] é apresentada.

\subsection{Método das características}

As mais simples equações diferenciais a serem tratadas são as de primeira ordem, para determinação de apenas uma função desconhecida. A integração de uma equação diferencial parcial deste tipo pode ser reduzida a uma família de problemas de valor inicial para um sistema de equações diferenciais ordinárias. Este é um resultado muito satisfatório em se considerando a disponibilidade de técnicas de resolução de equações diferenciais ordinárias.

A seguir vamos descrever brevemente a aplicação do método das características, de 


\section{Fluidos estáveis}

fundamental importância para os propósitos do trabalho de Stam [30]. O método das características pode ser usado para resolver equações diferenciais parciais com predominância convectiva, como por exemplo equações do tipo

$$
\frac{\partial}{\partial t} a(\mathbf{x}, t)=-\mathbf{v}(\mathbf{x}) \cdot \nabla a(\mathbf{x}, t)
$$

$a(\mathbf{x}, 0)=a_{0}(\mathbf{x})$, onde $a$ é um campo escalar, $\mathbf{v}$ é um campo vetorial e $a_{0}$ é o campo escalar no tempo $t=0$. Denotamos $\mathbf{p}\left(\mathbf{x}_{0}, t\right)$ as características do campo vetorial $\mathbf{v}$ passando por $\mathbf{x}_{0}$ em $t=0$

$$
\frac{d \mathbf{p}}{d t}\left(\mathbf{x}_{0}, t\right)=\mathbf{v}\left(\mathbf{p}\left(\mathbf{x}_{0}, t\right)\right)
$$

$\mathbf{p}\left(\mathbf{x}_{0}, 0\right)=\mathbf{x}_{0}$. Considere $\bar{a}\left(\mathbf{x}_{0}, t\right)=a\left(\mathbf{p}\left(\mathbf{x}_{0}, t\right), t\right)$ o valor do campo ao longo da característica passando pelo ponto $\mathbf{x}_{0}$ em $t=0$. A variação desta quantidade sobre o tempo pode ser calculada usando a regra da cadeia

$$
\frac{d \bar{a}}{d t}=\frac{\partial a}{\partial t}+\mathbf{v} \cdot \nabla a=0
$$

Isto mostra que o valor do escalar não varia ao longo das streamlines. Em particular, o campo inicial e as características definem a solução para o problema de advecção. O campo para um determinado instante de tempo $t$ e posição $\mathbf{x}$ é calculado traçando a posição $\mathbf{x}$ de volta no tempo ao longo das características para tomarmos o ponto $\mathbf{x}_{0} \mathrm{e}$, então, avaliar o campo inicial naquele ponto

$$
a\left(\mathbf{p}\left(\mathbf{x}_{0}, t\right), t\right)=a_{0}\left(\mathbf{x}_{0}\right)
$$

O método é utilizado para resolver a equação de advecção no intervalo de tempo $[t, t+\Delta t]$. Neste caso, $\mathbf{v}=\mathbf{u}(\mathbf{x}, t)$ e $a_{0}$ é qualquer das componentes de velocidade do fluido no tempo $t$.

\subsection{Teorema da decomposição de Helmholtz-Hodge}

Atualmente, diversos trabalhos são encontrados na literatura apresentando métodos de solução numérica para as equações de Navier-Stokes formuladas à partir de suas variáveis 


\section{Fluidos estáveis}

primitivas. Métodos de projeção são uma família de métodos numéricos que resolvem a equação da quantidade de movimento (2.3) separadamente em relação a equação da continuidade (2.2). Estes métodos são, por este motivo, chamados desacoplados e apresentam vantagens em sua implementação, uma vez que sofrem menos influências da nãolinearidade do termo convectivo e apresentam menor custo computacional se comparados aos métodos acoplados.

Os métodos de projeção são fundamentados em um importante teorema, conhecido como a decomposição de Helmholtz-Hodge. Este teorema é apresentado a seguir.

Teorema da decomposição de Helmholtz-Hodge. Seja $D$ uma região do plano com fronteira suave $\partial D$. Um campo vetorial $\mathbf{w}$ em $D$ pode ser unicamente decomposto na forma

$$
\mathbf{w}=\mathbf{u}+\nabla p,
$$

onde $p$ define um campo escalar e u possui divergente nulo e é paralelo a $\partial D$, ou seja, $\mathbf{u} \cdot \mathbf{n}=0$ em $\partial D, \mathbf{n}$ vetor normal a $\partial D$.

Prova. De início, é estabelecida a seguinte relação de ortogonalidade

$$
\int_{D} \mathbf{u} \cdot \nabla p d V=0
$$

Está relação está bem definida. De fato, considerando a seguinte identidade

$$
\nabla \cdot(p \mathbf{u})=(\nabla \cdot \mathbf{u}) p+\mathbf{u} \cdot \nabla p
$$

o teorema da divergência e admitindo $\nabla \cdot \mathbf{u}=0$, obtemos

$$
\int_{D} \mathbf{u} \cdot \nabla p d V=\int_{D} \nabla \cdot(p \mathbf{u}) d V=\int_{\partial D} p \mathbf{u} \cdot \mathbf{n} d A=0
$$

visto que $\mathbf{u} \cdot \mathbf{n}=0$ em $\partial D$. Esta relação de ortogonalidade é usada para provar a unicidade da decomposição. Supomos a existência de um vetor $\mathbf{w}$ tal que $\mathbf{w}=\mathbf{u}_{\mathbf{1}}+\nabla p_{1}$ e $\mathbf{w}=\mathbf{u}_{2}+\nabla p_{2}$, ou seja, apresentando duas decomposições nas condições do teorema. Dessa forma,

$$
\mathbf{u}_{1}+\nabla p_{1}=\mathbf{u}_{2}+\nabla p_{2}
$$




\section{Fluidos estáveis}

donde

$$
\mathbf{u}_{1}-\mathbf{u}_{2}+\nabla\left(p_{1}-p_{2}\right)=0
$$

Multiplicando ambos os lados dessa última igualdade pelo produto escalar entre $\mathbf{u}_{\mathbf{1}}-\mathbf{u}_{\mathbf{2}}$ e aplicando a integral, obtém-se

$$
0=\int_{D}\left[\left\|\mathbf{u}_{\mathbf{1}}-\mathbf{u}_{\mathbf{2}}\right\|^{2}+\left(\mathbf{u}_{\mathbf{1}}-\mathbf{u}_{\mathbf{2}}\right) \cdot \nabla\left(p_{1}-p_{2}\right)\right] d V=\int_{D}\left\|\mathbf{u}_{\mathbf{1}}-\mathbf{u}_{\mathbf{2}}\right\|^{2} d V
$$

pela relação de ortogonalidade. Segue portanto que $\mathbf{u}_{\mathbf{1}}=\mathbf{u}_{\mathbf{2}}$ e, daí, $\nabla p_{1}=\nabla p_{2}$.

Para provar a existência, sendo $\mathbf{w}=\mathbf{u}+\nabla p$, observa-se que $\nabla \cdot \mathbf{w}=\nabla \cdot \nabla p=\Delta p$ e $\mathbf{w} \cdot \mathbf{n}=\mathbf{n} \cdot \nabla p$. Dado o vetor $\mathbf{w}$, seja $p$ o campo definido pela solução do problema de Neumann

$$
\Delta p=\nabla \cdot \mathbf{w} \text { em } D, \operatorname{com} \frac{\partial p}{\partial n}=\mathbf{w} \cdot \mathbf{n} \text { na fronteira } \partial D
$$

Sabe-se que a solução para esse problema existe e é única ${ }^{1}$ até mesmo para o caso da adição de uma constante a $p$ [7]. À partir desta escolha de $p$, define-se $\mathbf{u}=\mathbf{w}-\nabla p$. Portanto, $\mathbf{u}$ satisfaz a propriedade desejada, ou seja, $\nabla \cdot \mathbf{u}=0$ e, também, $\mathbf{u} \cdot \mathbf{n}=0$ pela construção de $p$.

\subsection{O método estável de Stam}

\subsubsection{Ambiente computacional}

As equações governantes são muito úteis para o entendimento do comportamento de uma vasta gama de fluidos com diferentes propriedades. Entretanto, na prática é necessário providenciar uma discretização do contínuo, tornando finito o problema a ser estudado e viabilizando sua solução numérica através de computadores.

Stam [30] adotou uma malha regular quadrada, definida por sua origem, dimensões laterais com discretizações iguais em termos do espaçamento em $x$ e $y$ e número de células em cada coordenada. Dessa forma, tem-se $\Delta x=\Delta y=1 / N$, onde $N$ representa o número de células correspondente em uma direção com espaçamentos $\Delta x$ e $\Delta y$ nas direções $x$ e $y$, respectivamente. Uma camada adicional de células foi inserida na malha para facilitar

\footnotetext{
${ }^{1} \mathrm{~A}$ equação $\Delta p=f, \partial p / \partial n=g$ possui uma solução única se, e somente se, $\int_{D} f d V=\int_{\partial D} g d A$. O teorema da divergência garante que esta condição é satisfeita para este caso.
} 


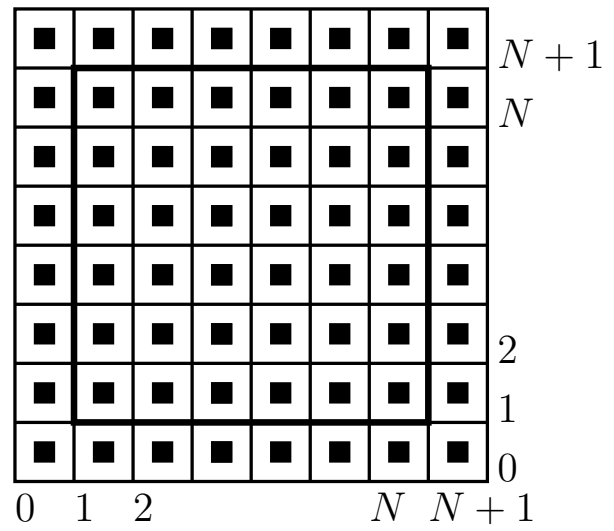

Figura 3.1: Ambiente computacional e armazenamento de propriedades [30].

o tratamento das condições de contorno. O fluido pode ser considerado como contido em uma caixa com paredes sólidas, não devendo ocorrer o escoamento para fora das paredes. Isto significa que as componentes normais da velocidade em relação a essas paredes devem ser nulas, ou seja, condições de contorno do tipo Neumann são impostas. Também, velocidades podem ser fixadas nestes contornos, caracterizando condições de contorno do tipo Dirichlet e possibilitando simular a entrada (inflow) e saída (outflow) de fluido no domínio computacional. Condições de contorno do tipo periódicas podem permitir que o fluido que sai por um lado da malha retorne ao domínio computacional pelo lado oposto. As condições de contorno podem ser de diferentes tipos para cada coordenada.

Os valores dos campos são discretizados com base no centro das células, conforme mostra a figura 3.1. A implementação requer também a alocação de dois vetores para cada componente da velocidade. A cada passo no tempo da simulação, um vetor fica responsável pelo armazenamento da solução obtida em um tempo anterior, enquanto o outro armazena a nova solução. Outros dois vetores são alocados para o campo escalar correspondente a substância transportada pelo fluido e a pressão.

À partir de um estado inicial para o campo de velocidades e o campo escalar, seus valores são atualizados de acordo com os eventos que acontecem no ambiente computacional. As próximas seções descrevem o desenvolvimento do algoritmo até a obtenção da atualização destes campos. 


\subsubsection{Atualização do campo de velocidades}

Um fluido cuja densidade e temperatura são necessariamente constantes é descrito por um campo de velocidades $\mathbf{u}=(u, v)$, em que $u$ e $v$ são suas componentes nas direções $x$ e $y$, respectivamente, e um campo da grandeza escalar pressão $p$, sendo portanto $\mathbf{x}=(x, y)$ a coordenada espacial cartesiana. Essas propriedades geralmente variam espacial e temporalmente e dependem das condições impostas ao contorno do fluido.

Dado que o campo de velocidades e pressão são conhecidos para um tempo inicial $t=0$, a evolução destas quantidades no tempo é dada pelas equações de Navier-Stokes (2.2-2.3). Como sabemos, as equações de Navier-Stokes são obtidas impondo que o fluido conserve ambos, massa (2.2) e momento (2.3). A pressão e o campo de velocidades que aparecem nas equações governantes estão, de fato, relacionadas.

De acordo com o teorema da decomposição de Helmholtz-Hodge, seção 3.2, qualquer campo vetorial $\mathbf{w}$ pode ser unicamente decomposto na forma

$$
\mathbf{w}=\mathbf{u}+\nabla q,
$$

onde $\mathbf{u}$ possui divergente nulo e $q$ é uma grandeza escalar, ou seja, qualquer campo vetorial define a soma de um campo vetorial que conserva massa e um campo gradiente. Este resultado permite definir um operador $\mathbf{P}$ que projeta qualquer campo vetorial $\mathbf{w} \mathrm{em}$ sua parte com divergente nulo $\mathbf{u}=\mathbf{P} \mathbf{w}$. O operador é definido implicitamente aplicando o divergente em ambos os lados da equação (3.2),

$$
\nabla \cdot \mathrm{w}=\nabla^{2} q
$$

a equação (3.3) define uma equação de Poisson para o campo escalar $q$ com condições de contorno de Neumann $\partial q / \partial n=0$ em $\partial D$. A solução dessa equação é utilizada para calcular a projeção $\mathbf{u}$

$$
\mathbf{u}=\mathbf{P} \mathbf{w}=\mathbf{w}-\nabla p .
$$

Aplicando o operador projeção $\mathbf{P}$ em ambos os lados da equação (2.3), obtemos a seguinte 


\section{Fluidos estáveis}

equação para o campo de velocidades

$$
\frac{\partial \mathbf{u}}{\partial t}=\mathbf{P}\left(-(\mathbf{u} \cdot \nabla) \mathbf{u}+\nu \nabla^{2} \mathbf{u}+\mathbf{f}\right)
$$

onde usamos o fato que $\mathbf{P u}=\mathbf{u}$ e $\mathbf{P} \nabla p=0$. Esta é a equação fundamental para o desenvolvimento do solver estável de escoamento de fluidos proposto.

A equação (3.4) é resolvida para um estado inicial de configuração do campo de velocidades $\mathbf{u}_{0}=\mathbf{u}(\mathbf{x}, 0)$ avançando no tempo com passo $\Delta t$. Suponha-se que o campo seja conhecido no instante $t$ e que deseja-se conhecer sua configuração no instante $t+\Delta t$. A equação (3.4) é resolvida em quatro passos. Inicia-se à partir da solução $\mathbf{w}_{0}(\mathbf{x})=\mathbf{u}(\mathbf{x}, t)$ no passo de tempo prévio e então sequencialmente se resolve cada termo do lado direito da equação, seguido por uma projeção. O procedimento geral é ilustrado na figura 3.2. Graficamente, os estágios podem ser descritos como abaixo

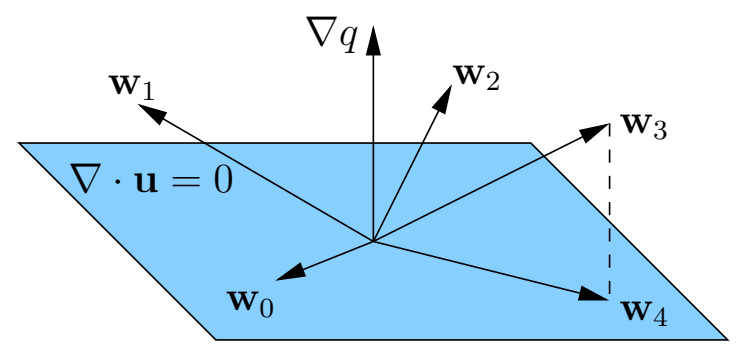

Figura 3.2: Esboço dos passos necessários para atualização do campo de velocidades.

$$
\mathbf{w}_{0}(\mathbf{x}) \stackrel{\text { força }}{\longrightarrow} \mathbf{w}_{1}(\mathbf{x}) \stackrel{\text { convecção }}{\longrightarrow} \mathbf{w}_{2}(\mathbf{x}) \stackrel{\text { difusão }}{\longrightarrow} \mathbf{w}_{3}(\mathbf{x}) \stackrel{\text { projeção }}{\longrightarrow} \mathbf{w}_{4}(\mathbf{x})
$$

A solução no tempo $t+\Delta t$ é dado pela atualização do campo de velocidades no último estágio $\mathbf{u}(\mathbf{x}, t+\Delta t)=\mathbf{w}_{4}(\mathbf{x})$. Uma simulação é obtida pela iteração desses estágios. A seguir é apresentado, mais detalhadamente, o desenvolvimento de cada estágio.

\section{Campo de forças}

O primeiro deles é o mais fácil de resolver e consiste da adição de uma força externa f no sistema. Assumindo que o módulo da força não varia consideravelmente durante o passo no tempo, então

$$
\mathbf{w}_{1}(\mathbf{x})=\mathbf{w}_{0}(\mathbf{x})+\Delta t \mathbf{f}(\mathbf{x}, t)
$$




\section{Fluidos estáveis}

define uma boa aproximação para o efeito resultante da força na configuração do fluido sobre o passo de tempo $\Delta t$. Em um sistema interativo, essa aproximação é aplicável, uma vez que as forças são consideradas apenas no início de cada passo no tempo.

\section{Convecção}

O próximo estágio diz respeito aos efeitos da convecção do fluido em si mesmo. Uma perturbação em algum lugar no fluido propaga-se de acordo com a expressão $-(\mathbf{u} \cdot \nabla) \mathbf{u}$. Esse termo torna as equações de Navier-Stokes não-lineares. Para sua resolução, Stam [30] adotou uma técnica de resolução de equações diferenciais parciais conhecida como método das características, seção 3.1. Sua adaptação ao método é de fundamental importância para o alcance da estabilidade incondicional. A cada passo no tempo, todas as partículas de fluido se movem devido ao campo de velocidades. Portanto, para obter a velocidade no ponto $\mathbf{x}$ no instante $t+\Delta t$, este é rastreado sobre o campo de velocidades $\mathbf{w}_{1}$ no tempo $\Delta t$. Este processo define um caminho $\mathbf{p}(\mathbf{x}, s)$ correspondente a linha de fluxo (streamline) parcial do campo de velocidades, figura 3.3. A nova velocidade no ponto $\mathbf{x}$ é então a

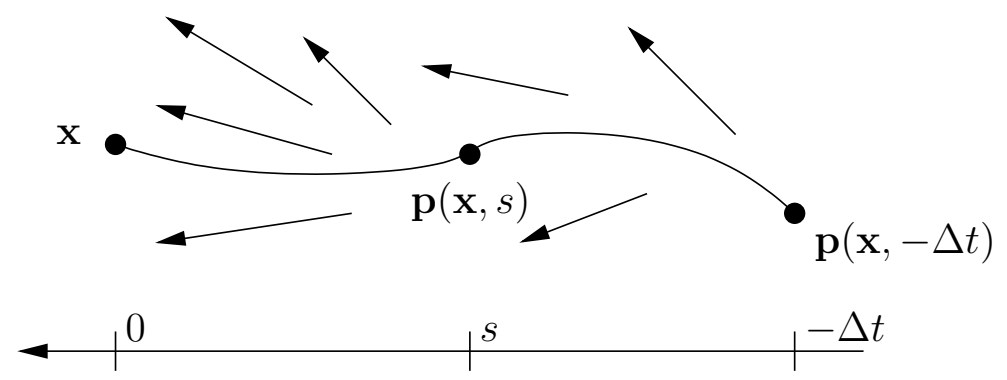

Figura 3.3: Resolução do termo convectivo via utilização do método das características.

velocidade que a partícula, agora em x, possuía em sua posição anterior em um tempo $\Delta t$ prévio

$$
\mathbf{w}_{2}(\mathbf{x})=\mathbf{w}_{1}(\mathbf{p}(\mathbf{x},-\Delta t))
$$

Desta forma, a estabilidade incondicional é garantida pelo fato de que, à partir da equação (3.5) tem-se que o valor máximo do novo campo de velocidades nunca será maior que o maior valor do campo anterior.

\section{Difusão}

O terceiro estágio é resolvido para os efeitos da viscosidade e é equivalente a resolver 


\section{Fluidos estáveis}

a seguinte equação de difusão

$$
\frac{\partial \mathbf{w}_{2}}{\partial t}=\nu \nabla^{2} \mathbf{w}_{2}
$$

Esta é uma equação padrão pelo qual muitos procedimentos numéricos são desenvolvidos. A maneira mais direta de resolvê-la é discretizar o operador difusão $\nabla^{2}$ e então explicitar a derivada temporal. Entretanto, este procedimento torna o método não estável quando se trabalha com um valor alto para a viscosidade. Stam [30] preferiu adotar um método implícito a partir do seguinte esquema

$$
\left(\mathbf{I}-\nu \Delta t \nabla^{2}\right) \mathbf{w}_{3}(\mathbf{x})=\mathbf{w}_{2}(\mathbf{x})
$$

onde I define o operador identidade. Assim sendo, ao ser discretizado, o operador difusão gera um sistema linear esparso para o campo desconhecido $\mathbf{w}_{3}$ que, entretanto, é resolvido eficientemente através do método iterativo de Gauss-Seidel.

\section{Projeção}

O quarto estágio diz respeito ao passo de projeção, que força o campo de velocidades resultante dos três estágios anteriores a conservar massa. Como mencionado anteriormente, este envolve a resolução do problema de Poisson definido pela equação (3.3). Considerando a pressão $p$ no sistema, obtemos

$$
\nabla^{2} p=\nabla \cdot \mathbf{w}_{3},
$$

de onde finalmente tem-se

$$
\mathbf{w}_{4}=\mathbf{w}_{3}-\nabla p .
$$

A equação de Poisson, assim como no estágio de difusão, quando discretizado espacialmente, gera um sistema linear esparso que também é resolvido de forma eficaz pelo método iterativo de Gauss-Seidel.

\subsubsection{Movendo substâncias no fluido}

A principal aplicação de um solver de escoamento de fluidos em computação gráfica consiste no uso do campo de velocidades para mover densidades ao seu redor realisticamente. Consequentemente, além de um solver de fluidos, animadores de efeitos gráficos 


\section{Fluidos estáveis}

também precisam de um modelo para a interação fluido-objeto. Determinadas substâncias são, portanto, modeladas à partir da definição de uma função densidade e estarão sujeitas aos efeitos de convecção e difusão impostos pelas equações governantes. Exemplificando, nuvens são modeladas através da atribuição de uma densidade de gotas de água para cada ponto do ambiente de interesse. Onde não há nuvem, o valor da densidade é simplesmente zero. Devemos observar que a densidade de tal substância não deve ser confundida com a densidade do fluido que, neste caso, é constante. Para tornar o método mais geral, Stam [30] menciona que essa densidade pode ser considerada uma grandeza escalar qualquer.

Seja a qualquer quantidade escalar ao entrar em contato com o fluido. A evolução temporal deste campo escalar é convenientemente descrito pela seguinte equação de convecção-difusão

$$
\frac{\partial a}{\partial t}=-(\mathbf{u} \cdot \nabla) a+\kappa_{a} \nabla^{2} a+S_{a},
$$

onde $\kappa_{a}$ é o coeficiente de difusão e $S_{a}$ um termo fonte. Esta equação é muito similar a equação de Navier-Stokes (2.3), apresentando um termo de convecção e outro de difusão, além do termo fonte. A maior diferença entre tais equações está presente no fato de que esta última equação é linear em $a$. À partir de uma configuração inicial do campo escalar considerado, os três termos da equação (3.8) podem ser resolvidos exatamente da mesma maneira que para a velocidade no fluido. O primeiro deles diz que a quantidade escalar deve acompanhar o campo de velocidades, figura 3.4, o segundo que a quantidade escalar sofre um processo de difusão a uma taxa $\kappa_{a}$, onde se assume que as trocas de
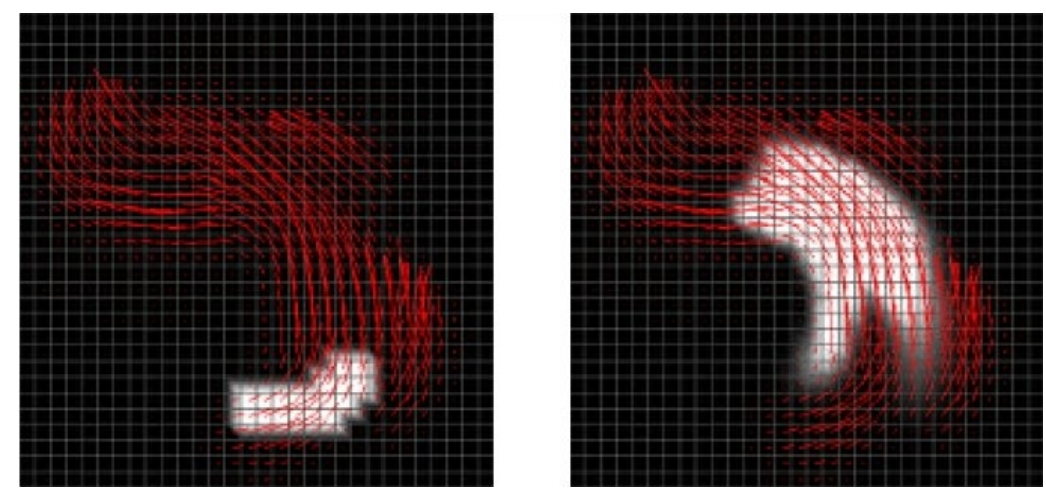

Figura 3.4: Campo escalar acompanhando o campo de velocidades [30].

informação entre células ocorrem apenas entre os quatro vizinhos diretos de uma célula simples, conforme mostra a figura 3.5. A figura 3.6 ilustra graficamente o efeito da difusão 


\section{Fluidos estáveis}

de uma substância em um ambiente.

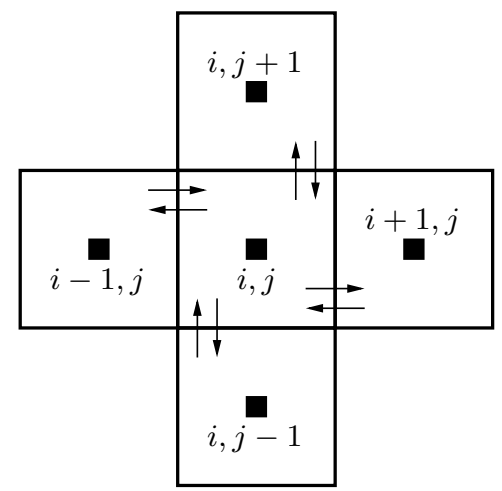

Figura 3.5: Troca de informações entre células.
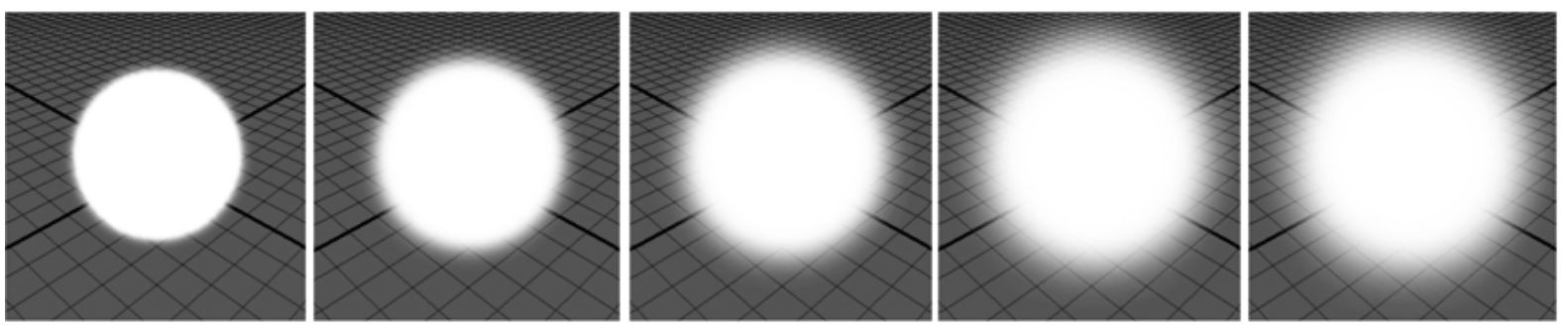

Figura 3.6: Ilustração dos efeitos da difusão em um campo escalar.

Por fim, o último termo implica que a quantidade escalar varia devido a ação de forças externas. O processo de simulação inicia com uma malha vazia de quantidades escalares e a atualização temporal se dá em três passos, que correspondem a cada termo da equação, comentados anteriormente. A figura 3.7 apresenta um esquema gráfico dos passos considerados no algoritmo.

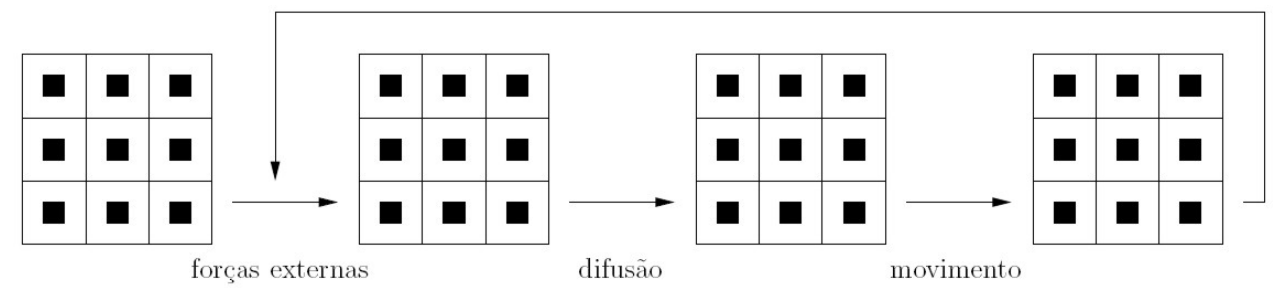

Figura 3.7: Passos para atualização da equação (3.8) [30].

As propriedades físicas do fluido são uma função de sua viscosidade. Variando a viscosidade, o programador pode simular uma extensa gama de substâncias. 
Fluidos estáveis 


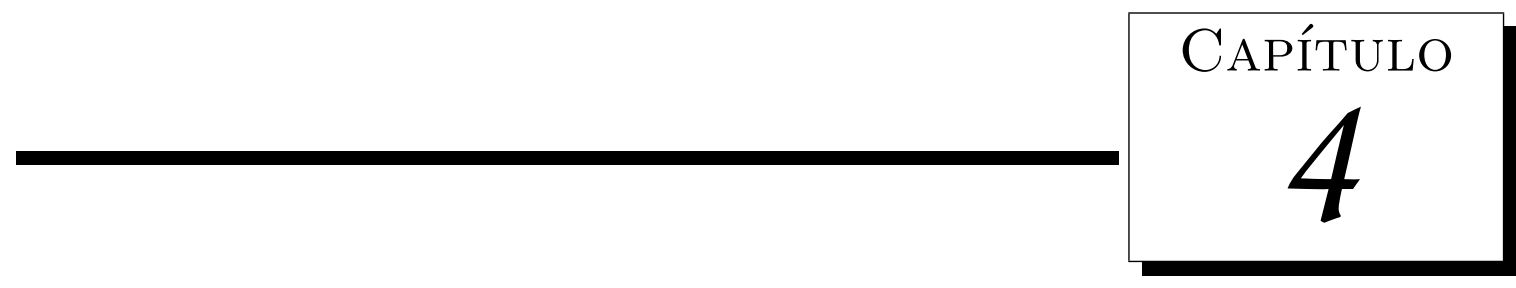

\section{Fronteira Imersa}

O "método da fronteira imersa" (MFI) foi desenvolvido por Charles Peskin [24] com o objetivo de simular numericamente uma classe de sistemas biológicos. À princípio, Peskin [24] direcionou seus estudos à simulação do escoamento sanguíneo no interior de um coração humano, onde as paredes dos músculos foram tratados como um conjunto de filamentos elásticos imersos no fluido. Após sua contribuição, diversos outros métodos foram desenvolvidos e aplicados a problemas da mecânica dos fluidos, possibilitando a simulação de escoamentos envolvendo interação entre fluido e superfícies sólidas e também entre fluidos diferentes e imiscíveis, entre outros. O MFI define, ao mesmo tempo, uma formulação matemática e um esquema numérico. A formulação matemática é baseada no uso das variáveis eulerianas para descrição da dinâmica do fluido e de variáveis lagrangeanas ao longo das estruturas móveis presentes no sistema. A força exercida por tais estruturas no fluido é fornecida por meio de uma função delta de Dirac, construída de acordo com certas propriedades. As condições de contorno não são impostas de forma direta e sim através de um campo de força avaliado sobre uma malha lagrangeana independente da malha adotada para obtenção da solução das equações de movimento. 


\subsection{Domínio computacional}

Uma das grandes dificuldades relacionadas a simulação numérica de problemas do mundo real consiste da transferência do domínio contínuo para um domínio discreto, onde se tornam viáveis manipulações computacionais. Para tornar possível o preenchimento da região de interesse, células resultantes do processo de discretização devem ser adequadamente definidas e adaptadas à sua geometria, podendo admitir formas bastante irregulares. Como sabemos, ao conjunto destas células ou dos pontos onde se poderá estabelecer soluções para um determinado conjunto de equações discretizado, associamos o nome malha. No caso da DFC, busca-se uma solução numérica independente da malha, ou seja, uma solução que não se altera, dentro de algum critério de tolerância, quando a malha é refinada.

Basicamente, existem dois tipos de malhas que frequentemente são utilizadas no desenvolvimento de um modelo numérico: malha estruturada, figura 4.1 e malha nãoestruturada, figura 4.2 .

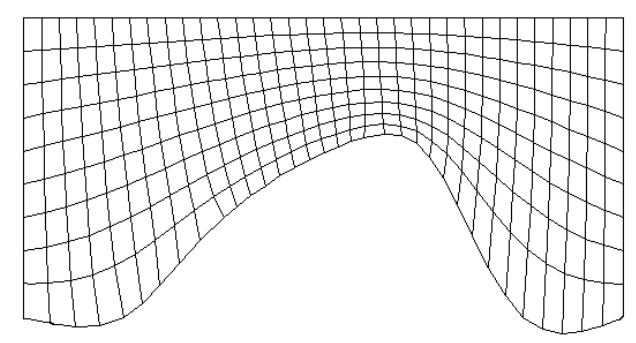

Figura 4.1: Discretização de um domínio irregular utilizando malha estruturada.

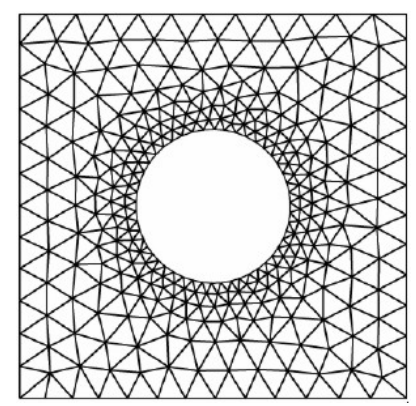

Figura 4.2: Discretização de um domínio irregular utilizando malha não-estruturada.

As malhas estruturadas apresentam uma estrutura, ou regularidade, na distribuição espacial dos pontos, o que não ocorre com as malhas não-estruturadas, que apresentam a 


\section{Fronteira Imersa}

incômoda desvantagem relacionada a dificuldade de obtenção de uma regra de ordenação para seu conjunto de pontos resultantes do processo de discretização. Pesam a favor das malhas estruturadas uma determinada facilidade de geração associada e o alto grau intuitivo dos algoritmos numéricos empregados na solução de problemas da DFC que utilizam desta malha. No entanto, o ganho em relação a adaptação das malhas nãoestruturadas em geometrias mais complexas é significativo devido à variedade de suas células.

Quando determinados objetos estão presentes no domínio do escoamento, a geração de uma malha robusta torna-se ainda mais difícil. Uma maneira apresentada pelos pesquisadores na tentativa de amenizar as dificuldades encontradas foi a adoção de esquemas de discretização coincidentes com a fronteira de objetos ou com interfaces entre fluidos diferentes, dando origem a métodos de fronteira adaptáveis (MFA) e métodos de fronteira imersa (MFI).

A geração de malha em MFA's consistem de duas partes: primeiro, uma malha superficial é definida, representando a geometria do objeto de uma maneira discreta. Então, algoritmos de geração de malha constroem uma malha estruturada ou não-estruturada para preencher o domínio do fluido, ou seja, o espaço entre a superfície do objeto e os contornos do domínio computacional, como pode ser visto na figura 4.3.
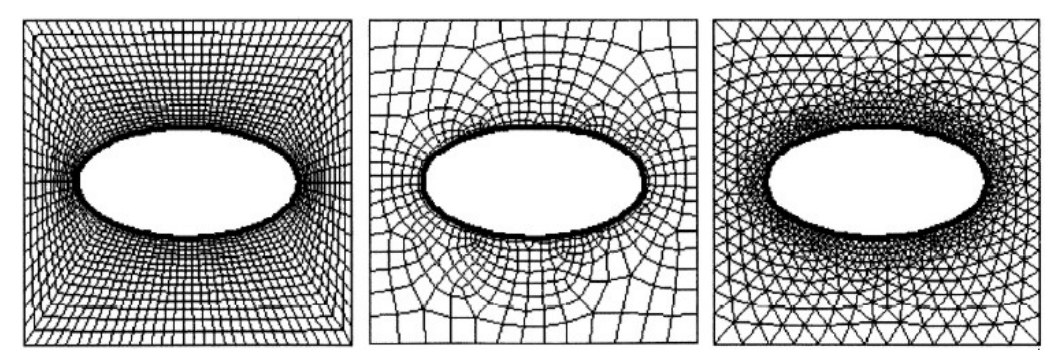

Figura 4.3: Malha estruturada (à esquerda) e malha não-estruturada (ao centro e à direita) adaptáveis à forma do objeto presente no fluido [19].

Nos MFI's, entretanto, a malha possui uma configuração mais simples. Uma malha cartesiana abrange todo o domínio computacional, incluindo o objeto imerso. Refinamentos locais na malha são possíveis nas proximidades da fronteira, o que é feito subdividindo células, conforme mostra a figura 4.4. A desvantagem deste método é que, em geral, não é possível impor diretamente as condições na fronteira, visto que não existe relação entre 


\section{Fronteira Imersa}
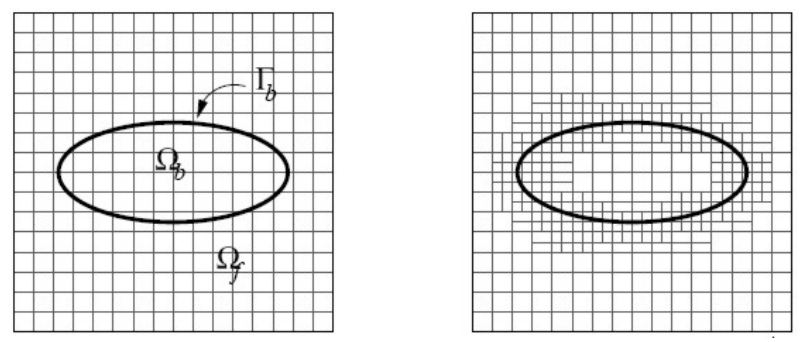

Figura 4.4: Malha cartesiana sem refinamentos locais (à esquerda) e com refinamentos locais próximos à fronteira imersa (à direita) [19].

a superfície do objeto e a posição dos pontos da malha. As condições de contorno são impostas pela inclusão de um termo extra nas equações governantes ou modificando o esquema numérico próximo a fronteira.

\subsection{O termo forçante}

Os métodos tradicionais de discretização de domínios apresentam certa morosidade em termos de implementação e custo computacional geralmente elevado. Tais características comuns podem ser basicamente atribuídas à necessidade sucessiva de remalhagem do domínio, além da necessidade de introduzir um novo sistema de coordenadas generalizadas. Conforme já mencionado, estes empecilhos incentivaram o desenvolvimento do MFI.

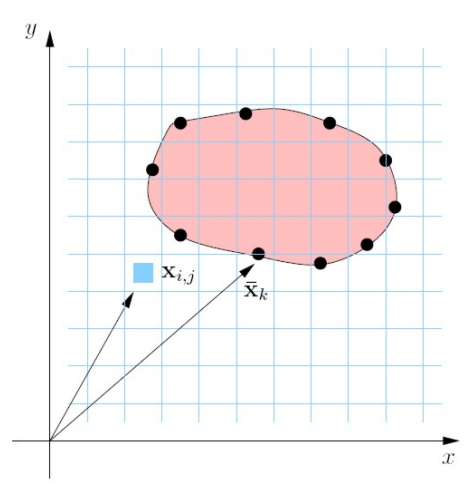

Figura 4.5: Representação das malhas euleriana e lagrangeana para um corpo imerso de geometria arbitrária.

O MFI estende um domínio de geometria irregular para um domínio de geometria retangular. A discretização é feita por dois tipos de malha, uma ortogonal que cobre todo o domínio (malha euleriana) e outra, formada por um conjunto de pontos, que representa 


\section{Fronteira Imersa}

apenas a interface delimitante do contorno (malha lagrangeana). A figura 4.5 ilustra um domínio de escoamento com interface imersa.

A interface delineada pela malha lagrangeana pode representar tanto o limite entre regiões ocupadas por dois fluidos diferentes, como também interfaces elásticas ou sólidas. Exceto no primeiro caso, todo o domínio é simulado como se fosse ocupado por um único fluido. As condições de contorno na interface são impostas virtualmente através de um campo de força aplicado ao escoamento. Este campo de força altera o vetor velocidade das partículas de fluido nas proximidades da interface imersa, figura 4.6. Assim, o fundamento básico do MFI consiste na estimativa de um termo forçante, fonte de força, que sugere a reação da interface sobre o fluido. Esse termo forçante é adicionado às equações de Navier-Stokes, forçando a condição de não-deslizamento sobre a interface. Isto induz que a velocidade de um elemento de fluido situado sobre a interface seja igual à própria velocidade da interface.

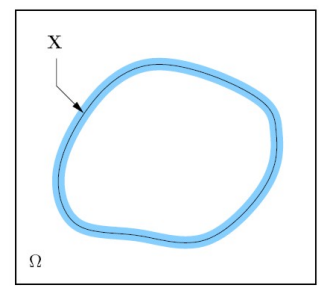

Figura 4.6: Região de ação do termo forçante (região sombreada) ao redor da interface $\mathrm{X}$.

Conforme se observa, a implementação das condições de contorno através da utilização do termo forçante é a chave no desenvolvimento de um método de fronteira imersa. Pode ser feito de diversas maneiras. O conceito geral é melhor explicado pelo uso de um exemplo abstrato [19].

Considere o sistema de equações diferenciais parciais que governam o escoamento de fluido acerca de um objeto, como na figura 4.4:

$$
\begin{aligned}
\Psi(\underline{\overline{\mathbf{u}}}) & =0 \quad \text { em } \Omega_{f}, \\
\operatorname{com} \underline{\overline{\mathbf{u}}} & =\underline{\overline{\mathbf{u}}}_{\Gamma} \quad \text { sobre } \Gamma_{b},
\end{aligned}
$$

onde $\underline{\overline{\mathbf{u}}}=(\mathbf{u}, p)$ e $\Psi$ define um operador em referência às equações governantes. O objeto 


\section{Fronteira Imersa}

possui um volume $\Omega_{b}$ e contorno $\Gamma_{b}$. O volume $\Omega_{f}$ é aquele ocupado pelo fluido. $\mathrm{O}$ tratamento do contorno "no infinito", exterior ao limite do domínio, não é importante ao se tratar de procedimentos básicos do método de fronteira imersa e, portanto, será ignorado. As equações discretizadas serão resolvidas em uma malha cartesiana que cobre todo o domínio computacional $\Omega=\Omega_{b}+\Omega_{f}$. Observamos que a condição de contorno $\underline{\underline{\mathbf{u}}}_{\Gamma}$ não está disponível para cada componente de $\underline{\overline{\mathbf{u}}}$ na fronteira imersa.

Nos métodos convencionais, seria formulada uma discretização da equação (4.1) em uma malha ajustada ao objeto, forçando a condição de contorno (4.2) diretamente. Métodos de fronteira imersa, entretanto, requerem uma modificação de (4.1) para tornar possível a imposição da condição de contorno. Em geral, essa modificação representa um termo forçante (ou função forçante) introduzido nas equações governantes que reproduzem o efeito do contorno. A introdução da função forçante nas equações governantes pode ser implementada de duas maneiras diferentes. Na primeira delas, a função forçante, denotada por $\mathbf{f}_{b}$, é adicionada ao lado direito da equação (4.1), obtendo $\Psi(\underline{\overline{\mathbf{u}}})=\left\{\mathbf{f}_{b}\right\}$ para todo o domínio $\Omega$. Observamos que $\mathbf{f}_{b}=\left(\mathbf{f}_{\mathbf{u}}, f_{p}\right)$, definindo funções forçantes que atuam nas componentes de velocidade e na pressão. Essa equação é discretizada em uma malha cartesiana com um esquema numérico apropriado, gerando um sistema de equações discretas

$$
[L]\{\underline{\overline{\mathbf{u}}}\}=\mathbf{f}_{b} .
$$

A equação (4.3) pode então ser resolvida no domínio completo $\Omega=\Omega_{b}+\Omega_{f}$. Essa aproximação recebe o nome de aproximação forçante contínua devido ao fato de o termo forçante ser introduzido no sistema antes de as equações constituintes serem discretizadas. O fato da formulação deste método ser independente do esquema de discretização espacial é uma de suas mais importantes características.

Em um segundo esquema de aproximação, ao invés da função forçante ser incluída diretamente nas equações governantes, as equações são primeiramente discretizadas sem referência a fronteira imersa, obtendo $[L]\{\underline{\underline{\mathbf{u}}}\}=0$. Em seguida, a discretização nas células próximas a fronteira imersa é ajustada levando em conta sua presença, o que resulta na definição do sistema de equações modificado $\left[L^{\prime}\right]\{\underline{\overline{\mathbf{u}}}\}=\{\mathbf{r}\}$, que é então resolvido na malha cartesiana. Nesta equação, $\left[L^{\prime}\right]$ define o operador discreto modificado e vetor $\{\mathbf{r}\}$ 


\section{Fronteira Imersa}

representa termos conhecidos associados às condições de contorno na superfície imersa. Para encontrarmos uma solução, $[L]\{\underline{\overline{\mathbf{u}}}\}=0$ necessita ser resolvido em $\Omega_{f}$, e

$$
\begin{gathered}
{[L]\{\underline{\overline{\mathbf{u}}}\}=\left\{\mathbf{f}_{b}^{\prime}\right\},} \\
\operatorname{com} \mathbf{f}_{b}^{\prime}=\{\mathbf{r}\}+[L]\{\underline{\overline{\mathbf{u}}}\}-\left[L^{\prime}\right]\{\underline{\overline{\mathbf{u}}}\}
\end{gathered}
$$

em $\Omega_{b}$.

O termo forçante foi agora introduzido após a discretização das equações. Este método, conhecido como aproximação forçante discreta, depende substancialmente do esquema de discretização. Em contrapartida, permite um controle direto sobre a precisão numérica, estabilidade e conservação das propriedades discretas do solver.

A diferença básica entre as diversas metodologias de fronteira imersa consiste na determinação da força sobre os pontos interfaciais (dita força lagrangeana) e na forma de disseminar esta força sobre o escoamento (gerando a força euleriana). Na seção seguinte, alguns métodos são apresentados e classificados de acordo com as aproximações descritas nesta seção [19].

\subsection{Aproximação forçante contínua}

Fronteiras rígidas e elasticamente deformáveis requerem um tratamento diferente em uma formulação fundamentada no MFI. Essa diferença nos direciona a tratá-las de forma separada nas próximas subseções.

\subsubsection{Fronteiras elasticamente deformáveis}

Fronteiras elasticamente deformáveis abrange a classe de problemas que Peskin [24] tinha em mente quando desenvolveu o primeiro método da fronteira imersa. Este método resolve as equações de Navier-Stokes em uma malha cartesiana estacionária, sendo a fronteira imersa representada por um conjunto de fibras elásticas que se movem de acordo com a velocidade local do escoamento. A coordenada vetorial $\overline{\mathbf{x}}_{k}$ do $k$-ésimo ponto lagrangeano é obtida à partir do fato que a derivada temporal da posição da fibra equivale 


\section{Fronteira Imersa}

à velocidade do fluido naquele ponto

$$
\frac{\partial \overline{\mathbf{x}}_{k}}{\partial t}=\mathbf{u}\left(\overline{\mathbf{x}}_{k}, t\right)
$$

O "stress" $\mathbf{F}$ e a deformação das fibras são relacionadas pela lei de Hooke ou uma relação similar. Finalmente, o efeito da fronteira imersa no escoamento pode ser incorporado através da inclusão de um termo forçante nas equações de momento do fluido. Desta forma, um termo forçante local $\mathbf{f}_{m}(\mathbf{x}, t)$ transfere o stress das fibras para o escoamento segundo a equação

$$
\mathbf{f}_{m}(\mathbf{x}, t)=\sum_{k} \mathbf{F}_{k}(t) \delta\left(\left|\mathbf{x}-\overline{\mathbf{x}}_{k}\right|\right)
$$

onde $\delta$ representa a função delta de Dirac. Porém, observado que em geral a localização das fibras não coincide com os pontos nodais da malha cartesiana, a função delta de Dirac não é útil para a transferência dos efeitos do termo forçante a esta malha. Assim sendo, a função $\delta$ é substituída por uma função de distribuição suave $d$ que "espalha" os efeitos do termo forçante para um conjunto de células próximo a cada partícula lagrangeana, figura 4.7.
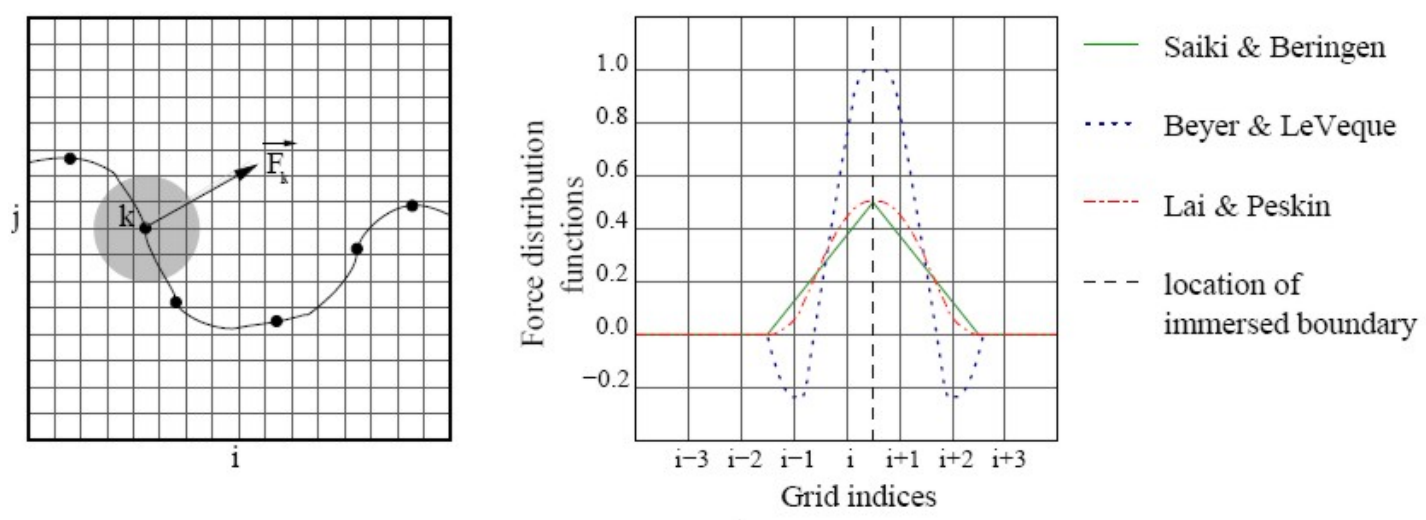

Figura 4.7: O stress em um ponto lagrangeano $k$ propaga-se sobre seus vizinhos na malha (região sombreada) devido a função de distribuição [19].

O termo forçante em qualquer ponto $\mathbf{x}_{i, j}$ da malha cartesiana em consequência das forças elásticas nas fibras é avaliado de acordo com a seguinte equação

$$
\mathbf{f}_{m}\left(\mathbf{x}_{i, j}, t\right)=\sum_{k} \mathbf{F}_{k}(t) d\left(\left|\mathbf{x}_{i, j}-\overline{\mathbf{x}}_{k}\right|\right)
$$




\section{Fronteira Imersa}

A mesma função de distribuição suave $d$ é utilizada para calcular a velocidade da fibra segundo a equação (4.4), ou seja, a velocidade nos pontos lagrangeanos que definem a interface.

Obviamente, a função de distribuição desempenha um importante papel, pois é a responsável pela transferência das forças elásticas ao fluido e caracteriza a nova posição da fronteira imersa.

O método descrito nesta subseção para o tratamento de fronteiras elasticamente deformáveis foi aplicado de maneira satisfatória para muitos problemas da área biológica e envolvendo escoamentos multifásicos.

\subsubsection{Fronteiras rígidas}

Quando a fronteira imersa é rígida, as limitações da técnica desenvolvida por Peskin [24] vão logo se tornando aparentes. Fronteiras rígidas são aquelas em que o pontos discretos estão rigidamente interligados. Isto contudo não impede o possível caráter transiente dessas interfaces, as quais podem apresentar conformações diferentes para cada nível de tempo. O principal problema é que as leis constitutivas, como a lei de Hooke, não são, geralmente, bem postas no limite rígido. Uma maneira de enfrentar esse problema é assumir que o objeto é elástico, mas extremamente consistente. Outra técnica assume que a estrutura/contorno seja anexada a uma posição de equilíbrio por uma "mola", caracterizando essa uma força restauradora $\mathbf{F}[4,17]$, dada por

$$
\mathbf{F}_{k}(t)=-\kappa\left(\mathbf{x}_{k}-\overline{\mathbf{x}}_{k}^{e}\right)
$$

onde $\kappa$ representa uma constante "mola" positiva e $\overline{\mathbf{x}}_{k}^{e}$ a posição de equilíbrio do $k$-ésimo ponto lagrangeano. A imposição precisa das condições de contorno na fronteira rígida requer um valor alto para a constante $\kappa$, uma vez que pequenos valores podem forçar o contorno a desviar excessivamente de sua posição de equilíbrio, o que claramente não caracteriza de forma realística um objeto rígido. Em consequência, quando esquemas de integração explícitos são considerados, acabam acarretando uma limitação no passo temporal para que o sistema seja mantido estável. Por sua vez, a adoção destes esquemas ocasionam um aumento considerável em termos de sobrecarga computacional. 


\section{Fronteira Imersa}

Uma versão generalizada para a formulação anterior foi proposta por Goldstein et al. [12]. Entretanto, apresentou os mesmos problemas de estabilidade, por sua vez ocasionados devido a grandes valores associados às constantes de "rigidez", necessárias nesta aproximação para modelar o contorno rígido precisamente.

\subsection{Aproximação forçante discreta}

Os métodos inseridos no âmbito desta aproximação são classificados em métodos que apliquem as condições de contorno diretamente sobre a fronteira imersa e métodos que impõem as condições de contorno indiretamente. O primeiro destes é aplicável a escoamentos associados a altos números de Reynolds ${ }^{1}$, onde o segundo não é bem sucedido. Sua formulação utiliza células fantasmas e esquemas de interpolação individuais a estas que possibilitam incorporar a condição de contorno na fronteira imersa [19]. A seguir, apresentamos uma descrição mais detalhada da segunda abordagem, importante para nosso trabalho.

\subsubsection{Imposição indireta da condição de contorno}

A imposição indireta da condição de contorno significa simplesmente que esta condição de contorno não é usada diretamente no esquema numérico. Ao invés disto, um termo forçante é adicionado ao sistema discreto das equações governantes nas células próximas à fronteira imersa. O termo forçante é derivado das condições de contorno, ao contrário do que veremos na outra abordagem, onde o mesmo é determinado usando relações da mecânica. Em geral, a obtenção do termo forçante é feito estimando o campo de velocidades e, em seguida, corrigindo-o para se ajustar às condições de fronteira. São raros os casos em que o termo forçante pode ser obtido analiticamente [4].

Mohd-Yossuf [20] e Verzicco et al. [33] desenvolveram um método que extrai o termo forçante diretamente à partir da solução numérica para que, a priori, uma estimativa possa ser determinada. Iniciando à partir das equações de Navier-Stokes discretizadas sem qualquer modificação devido a presença da fronteira imersa, considerando a mesma notação da seção 4.2 , o sistema $[L]\left\{\underline{\mathbf{u}}^{*}\right\}=0$ é resolvido a cada passo no tempo, onde $\left\{\underline{\mathbf{u}}^{*}\right\}$ representa um preditor do campo de velocidades. O termo forçante $\left\{\mathbf{f}_{b}^{\prime}\right\}$ na equação (4.2)

\footnotetext{
${ }^{1}$ Razão entre as forças inerciais e as forças viscosas do escoamento.
} 


\section{Fronteira Imersa}

é definido como

$$
\left\{\mathbf{f}_{b}^{\prime}\right\} \approx\{\mathbf{r}\}+[L]\left\{\underline{\overline{\mathbf{u}}}^{*}\right\}-\left[L^{\prime}\right]\left\{\underline{\mathbf{u}}^{*}\right\}=\{\mathbf{r}\}-\left[L^{\prime}\right]\left\{\underline{\mathbf{u}}^{*}\right\}
$$

onde $\{\mathbf{r}\}=\left\{\underline{\underline{\mathbf{u}}}_{\Gamma}\right\} \delta\left(\left|\overline{\mathbf{x}}_{k}-\mathbf{x}_{i, j}\right|\right)$ e $\left[L^{\prime}\right]=[L]+([I]-[L]) \delta\left(\left|\overline{\mathbf{x}}_{k}-\mathbf{x}_{i, j}\right|\right)$, sendo $[I]$ a matriz identidade. A função delta de Dirac é substituída por uma função de distribuição suave $d$ e, portanto, a equação (4.2) adquire a seguinte forma

$$
[L]\{\underline{\overline{\mathbf{u}}}\}=\left\{\underline{\overline{\mathbf{u}}}_{\Gamma}-\underline{\overline{\mathbf{u}}}^{*}\right\} d\left(\left|\overline{\mathbf{x}}_{k}-\mathbf{x}_{i, j}\right|\right)+[L]\left\{\underline{\overline{\mathbf{u}}}^{*}\right\} d\left(\left|\overline{\mathbf{x}}_{k}-\mathbf{x}_{i, j}\right|\right),
$$

que formalmente representa a aplicação da condição de contorno na posição $\overline{\mathbf{x}}_{k}$ da fronteira imersa. 
Fronteira Imersa 


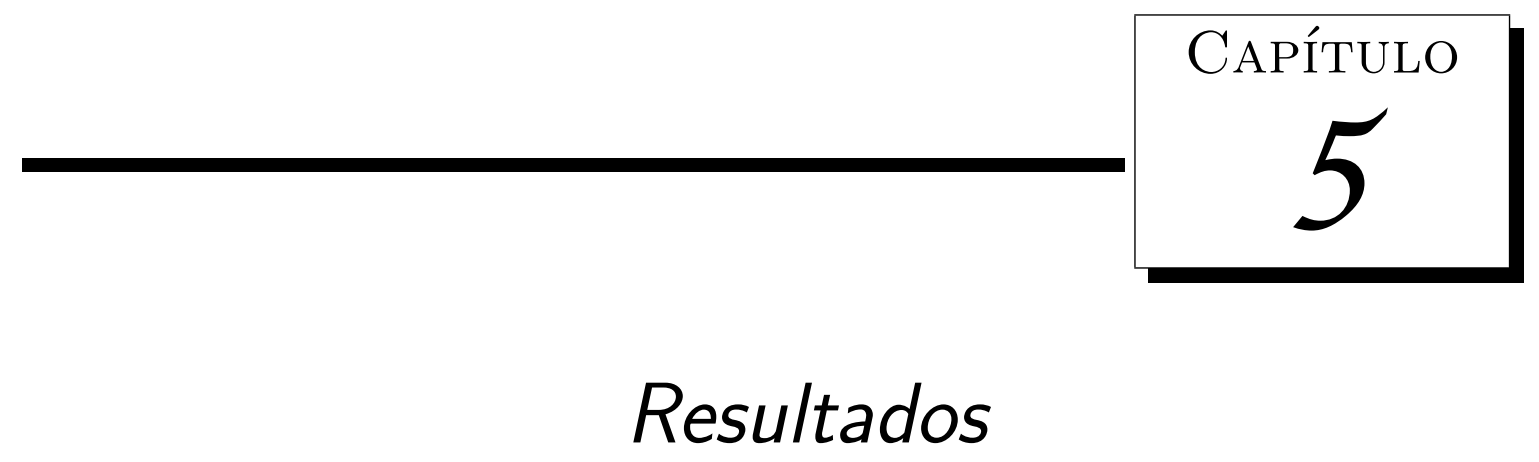

Este capítulo apresenta os resultados obtidos à partir da implementação dos métodos descritos nos capítulos 3 e 4. Inicialmente comentamos a estrutura do solver desenvolvido, para posteriomente apresentar os resultados obtidos.

\subsection{Estrutura do solver}

O código final foi desenvolvido na linguagem de programação $\mathrm{C}++$ juntamente com um visualizador baseado na $\mathrm{API}^{1}$ OpenGL, umas das mais utilizadas na visualização científica. A estrutura do código desenvolvido divide-se em classes responsáveis pelo conjunto de dados e métodos necessários para obtenção dos resultados numéricos que, posteriormente, são visualizados.

Inicialmente, o programa é responsável pela criação da malha computacional à partir dos dados obtidos da imagem a ser trabalhada. Esta imagem deve ser apresentada em formato $\mathrm{pgm}^{2}$, definindo as dimensões do domínio computacional e condicionando os valores para a viscosidade de fluidos diferentes. Os pontos da imagem, denominados pixels, que caracterizam as propriedades de interesse em seu conjunto formam a imagem

\footnotetext{
${ }^{1}$ Interface de Programação de Aplicativos (do inglês Application Programming Interface).

${ }^{2}$ Imagem portátil mapeada em escala de cinza (do inglês Portable Gray Map).
} 


\section{Resultados}

representada.

A figura 5.2(a) apresenta um exemplo de uma imagem definida em formato pgm. O cabeçalho de imagens pgm apresenta-se no formato texto, apresentado na figura 5.2(b). A primeira linha indica o formato de representação da imagem, podendo ser textual com 1 caracter por byte (P2) ou compactada (P5). A segunda linha informa o nome do software onde a imagem foi criada. A terceira indica o tamanho horizontal $(M)$ e vertical $(N)$ da imagem, respectivamente. A quarta representa o número máximo de níveis de cinza, geralmente assumindo o valor 255. À partir da quinta linha são descritos os valores individuais de nível de cinza para cada pixel. Nas imagens P5, tais valores apresentam-se no formato binário, onde cada byte representa o brilho de um pixel. Nas imagens P2, estão no formato texto, onde cada número inteiro representa o brilho de um pixel, estando os brilhos separados por espaços em branco. Os valores começam na posição $(0,0)$ no canto superior esquerdo e vão até a posição $(M, N)$ no canto inferior direito, varrendo toda a imagem.

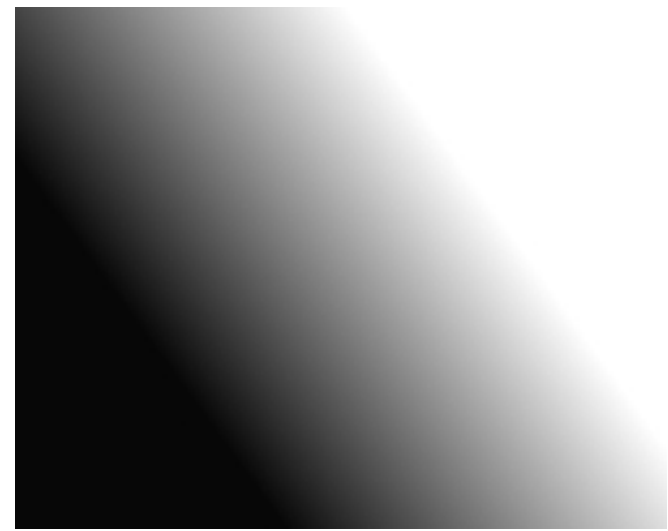

(a) Visualização.

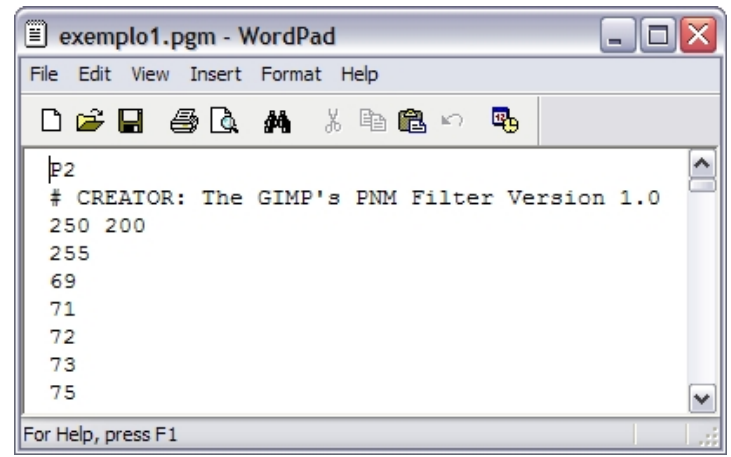

(b) Estrutura da imagem.

Figura 5.1: Imagem no formato pgm.

Em seguida, todas as matrizes que armazenam os valores de velocidade e pressão são definidas e inicializadas, bem como as matrizes necessárias à resolução do sistema de equações discretizado de acordo com a metodologia de Jos Stam [30], capítulo 3, e também as matrizes auxiliares necessárias à adoção do MFI, capítulo 4. Classes específicas estão implementadas, possuindo funções membro auxiliares para manipulação iterativa dos elementos das matrizes e vetores definidos e alocados dinamicamente. 


\section{Resultados}

Uma diferença neste trabalho em relação a formulação de Stam consiste na adaptação do algoritmo de Liang-Barsky [14] para o desenvolvimento do esquema semi-lagrangeano para resolução do termo convectivo da equação (2.3).

Em decorrência da existência do operador laplaciano e da formulação de nosso problema, as equações apresentadas em 3.6 e 3.7 quando discretizadas dão origem a sistemas lineares cuja matriz dos coeficientes é não-simétrica, o que impõe restrições na escolha do método para sua resolução. Um método iterativo que trabalha sobre essa hipótese de modo eficiente é o método dos gradientes bi-conjugados (MGbC), apresentado no apêndice A. Sua aplicação foi considerada, apresentando bons resultados. Os critérios de parada adotado apontam para um número máximo de iterações ou obtenção de um resíduo mínimo pré-estabelecidos pelo programador. Para as simulações descritas nas seções 5.2 e 5.3 foi considerado um valor máximo de 2000 iterações e resíduo igual a $10^{-10}$.

Também estão implementados esquemas de interpolação espacial, importantes técnicas que permitem o transporte de propriedades à partir de informações conhecidas de seus vizinhos mais próximos. Para realizar a interpolação, iniciamos com duas malhas, uma que contém os valores da tonalidade de cinza de um pixel em um tempo anterior e outra que contém tal informação no tempo corrente.

Nas seções seguintes são apresentados os resultados obtidos pela formulação de nosso problema. Como comentado, as equações governantes que caracterizam nossa formulação, ou seja, as equações de Navier-Stokes (2.2-2.3), são resolvidas de acordo com a metodologia de Jos Stam [30], assim como a equação de transporte (3.8). A imposição das condições de contorno na região de interesse não se dá de maneira direta, como nos métodos tradicionais. Aqui, consideramos a aplicação do MFI, cuja descrição encontra-se na seção 4.4 do capítulo 4.

\subsection{Viscosidade constante}

Em todas as simulações que descreveremos abaixo, consideramos o espaçamento da malha na horizontal e na vertical iguais a 1 , ou seja, tem-se $\Delta x=\Delta y=1$. Os outros parâmetros que caracterizam a simulação são descritos individualmente.

Na primeira simulação, consideramos uma imagem de tamanho $200 \times 200$ pixels, figura 


\section{Resultados}

5.2(a). Para demonstrar os efeitos da metodologia adotada, restringimos a atuação direta da força inserida no sistema para a região demonstrada na figura 5.2(b). Esta força tende a deslocar o fluido no sentido contrário a orientação espacial em $y$.

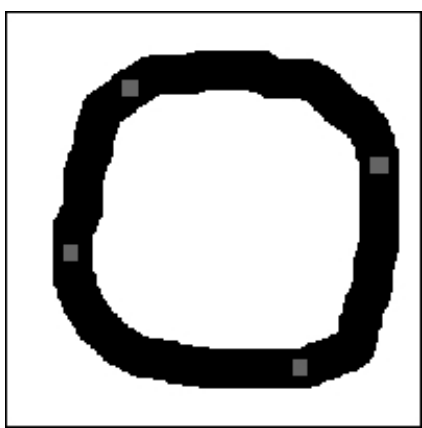

(a) Imagem.

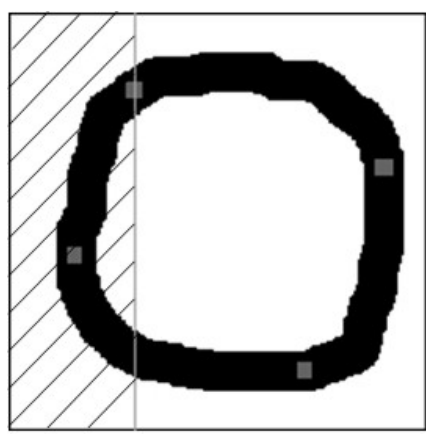

(b) Restrição no domínio computacional.

Figura 5.2: Primeira simulação.

Os resultados obtidos evidenciam a atuação direta da força mencionada na região considerada. Nesta simulação os valores considerados para o espaçamento temporal, viscosidade cinemática e componente vertical da força são tais que $\Delta t=0.3, \nu=100 \mathrm{e}$ $f_{y}=-10$, respectivamente. As figuras 5.3(a), 5.3(b) e 5.3(c) apresentam a configuração do perfil de velocidades em $x$, em $y$, da pressão e a imagem resultante, respectivamente. A paleta de cores localizada no alto das figuras indica o valor mínimo e máximo das propriedades em questão no momento em que ocorre o número de iterações mencionado. Nas figuras 5.3, 5.4 e 5.5 estão apresentados os dados do escoamento para 10, 20 e 30 iterações, respectivamente. A rápida deterioração da imagem ocorre devido ao alto valor associado ao espaçamento temporal $\Delta t$. Observamos também que os mais altos valores, em módulo, para as componentes da velocidade e para a pressão são encontrados na região em que a força é aplicada diretamente.

A simulação que segue tem como base os mesmos dados da simulação anterior no que diz respeito ao valor da viscosidade cinemática e da força atuante no sistema. No entanto, a componente vertical da força externa deixa de ser restrita e passa a agir em todo o domínio computacional. O valor da constante de variação temporal passa a valer $\Delta t=0.17$. Percebe-se, dessa forma, uma distribuição mais homogênea para o perfil de velocidades e pressão, resultando em uma imagem mais harmoniosa. As figuras 5.6, 5.7 


\section{Resultados}

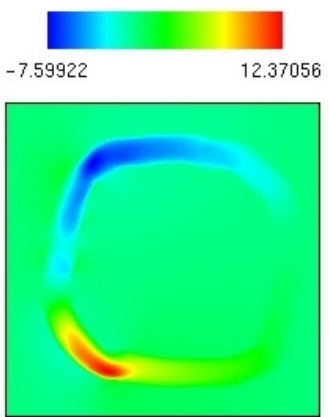

(a) Velocidade em $x$.

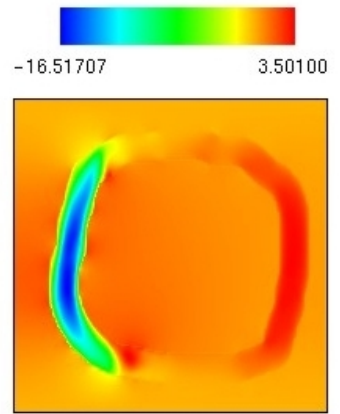

(b) Velocidade em $y$.

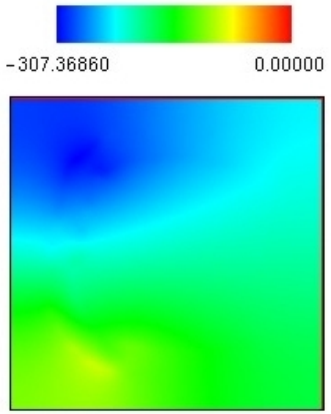

(c) Pressão.

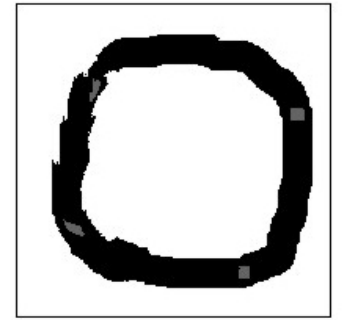

(d) Imagem resultante.

Figura 5.3: Configuração após 10 iterações.

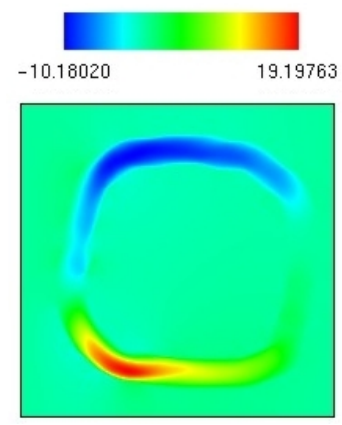

(a) Velocidade em $x$.

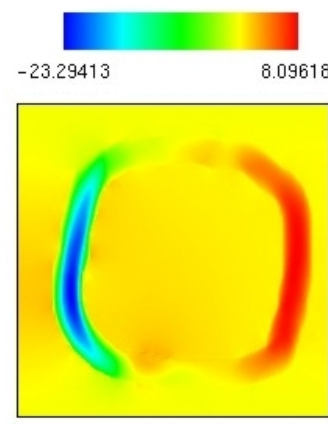

(b) Velocidade em $y$.

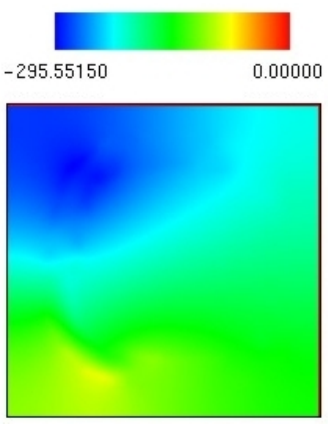

(c) Pressão.

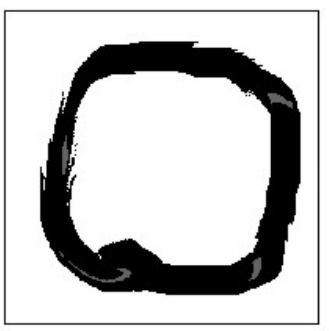

(d) Imagem resultante.

Figura 5.4: Configuração após 20 iterações.

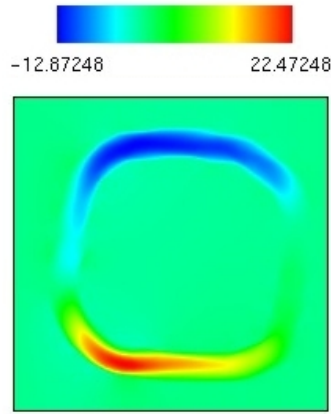

(a) Velocidade em $x$.

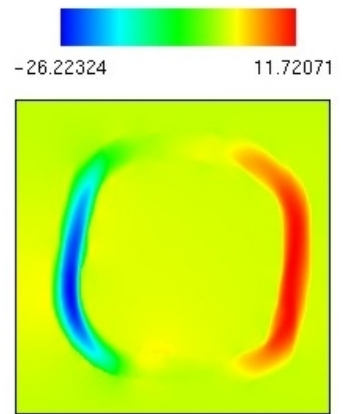

(b) Velocidade em $y$.

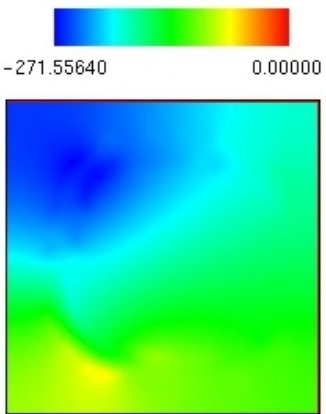

(c) Pressão.

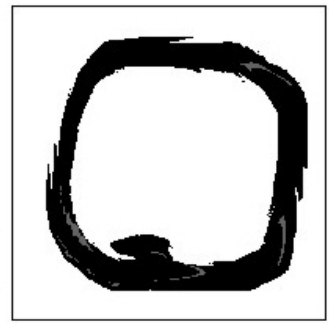

(d) Imagem resultante.

Figura 5.5: Configuração após 30 iterações.

e 5.8 apresentam os dados do escoamento para 10, 20 e 30 iterações, respectivamente. Para efeito de comparação, a figura 5.10 apresenta a evolução da configuração da imagem 5.2 (a) de acordo com diferentes números de iterações para $\Delta t=0.14$. 


\section{Resultados}

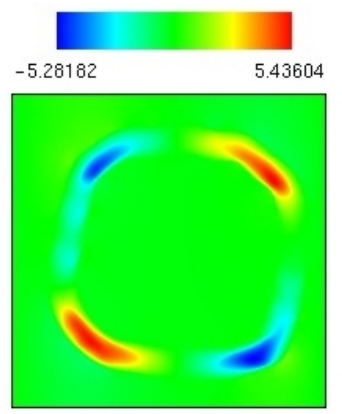

(a) Velocidade em $x$.

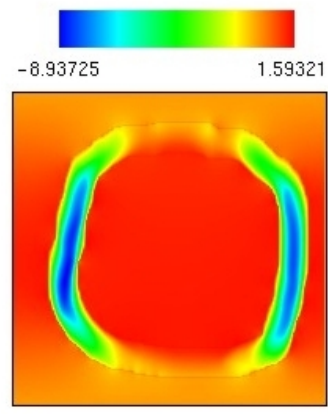

(b) Velocidade em $y$.

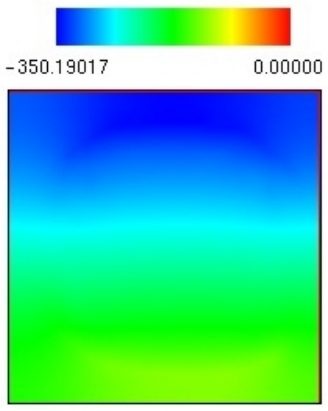

(c) Pressão.

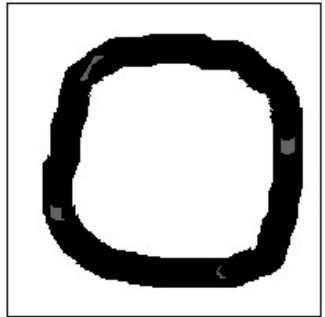

(d) Imagem resultante.

Figura 5.6: Configuração após 10 iterações.

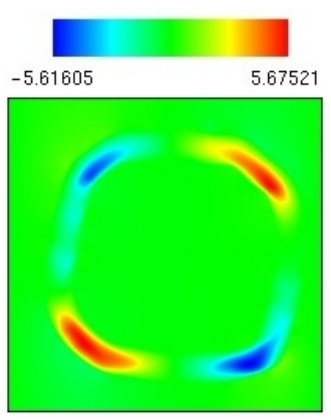

(a) Velocidade em $x$.

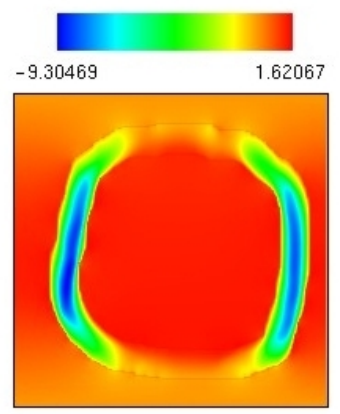

(b) Velocidade em $y$.

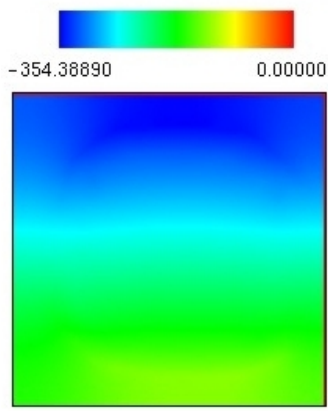

(c) Pressão.

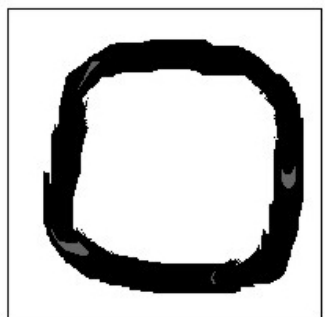

(d) Imagem resultante.

Figura 5.7: Configuração após 20 iterações.

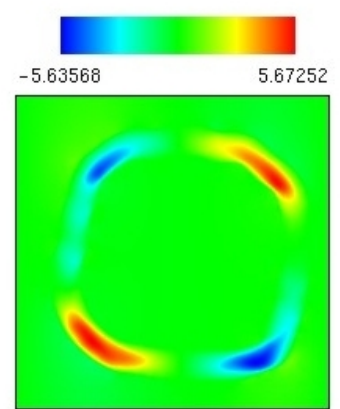

(a) Velocidade em $x$.

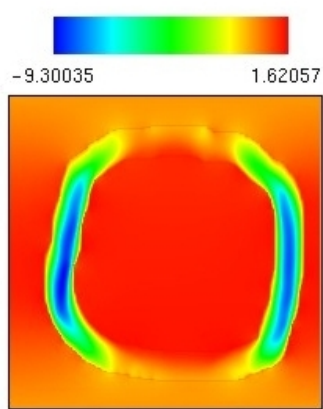

(b) Velocidade em $y$.

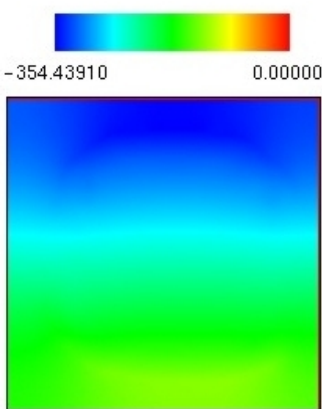

(c) Pressão.

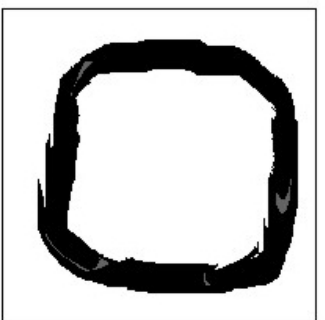

(d) Imagem resultante.

Figura 5.8: Configuração após 30 iterações.

A próxima simulação é realizada em uma imagem de tamanho $150 \times 150$ pixels, figura 5.9. Para este escoamento, consideramos $\nu=80, \Delta t=0.15$ e $f_{y}=-10$. O perfil das componentes da velocidade e da pressão após 10, 50 e 90 iterações, respectivamente, podem ser observadas nas figuras 5.11, 5.12 e 5.13. Por fim, a figura 5.14 apresenta a 


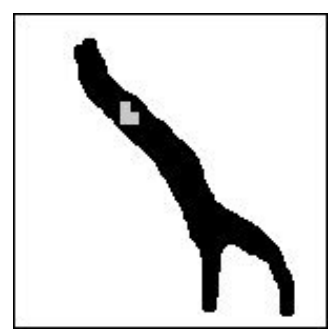

Figura 5.9: Imagem considerada na terceira simulação.

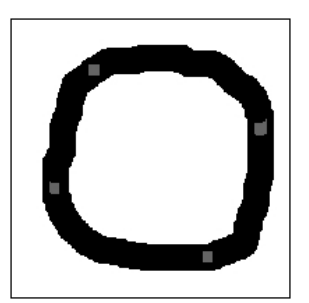

(a) 10 iterações.

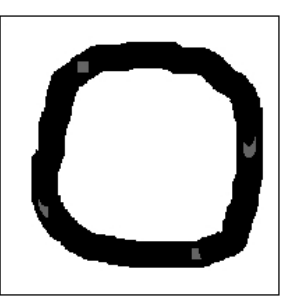

(b) 30 iterações.

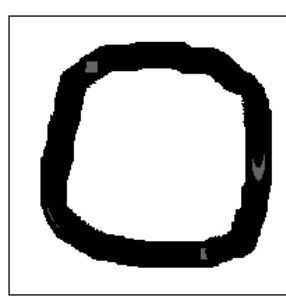

(c) 50 iterações.

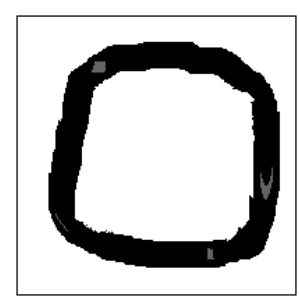

(d) 70 iterações.

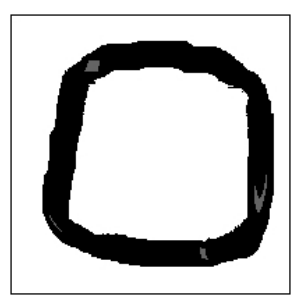

(e) 90 iterações.

Figura 5.10: Evolução da imagem pictoral após sucessivas iterações.

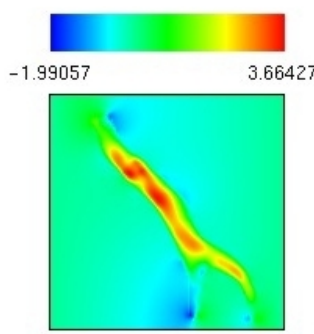

(a) Velocidade em $x$.

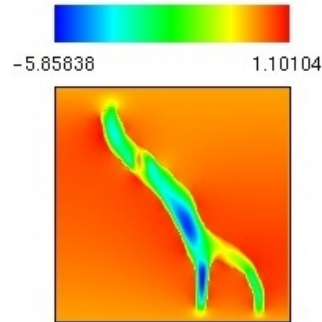

(b) Velocidade em $y$.

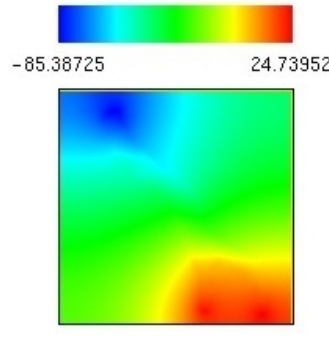

(c) Pressão.

Figura 5.11: Configuração após 10 iterações.

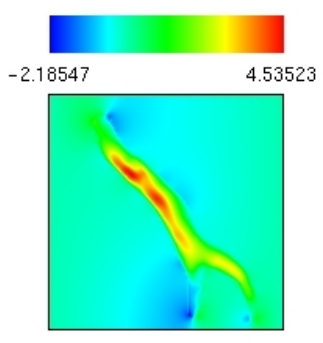

(a) Velocidade em $x$.

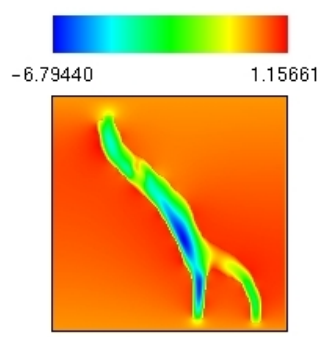

(b) Velocidade em $y$.

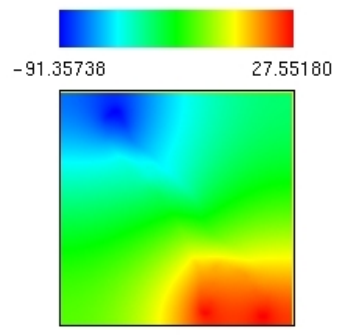

(c) Pressão.

Figura 5.12: Configuração após 50 iterações.

evolução da configuração da imagem após sucessivas iterações do método proposto.

Por fim, as imagens da figura 5.14 apresentam a evolução da configuração da imagem 


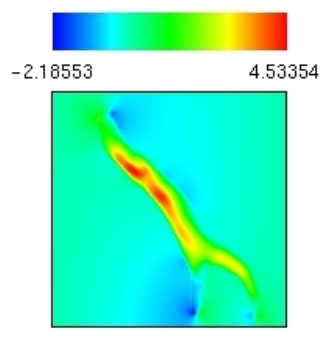

(a) Velocidade em $x$.

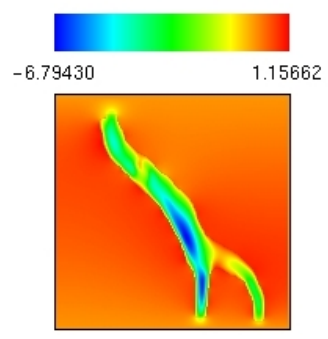

(b) Velocidade em $y$.

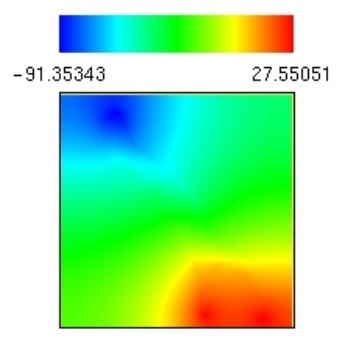

(c) Pressão.

Figura 5.13: Configuração após 90 iterações.

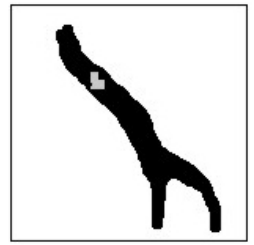

(a) 10 iterações.

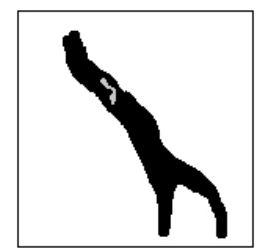

(b) 30 iterações.

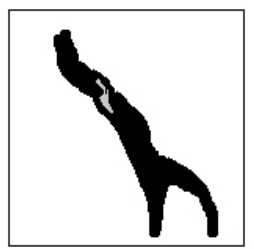

(c) 50 iterações.

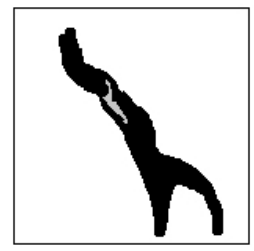

(d) 70 iterações.

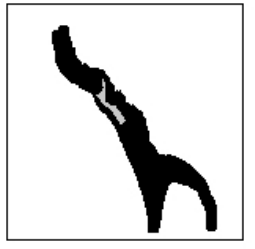

(e) 90 iterações.

Figura 5.14: Evolução da imagem pictoral após sucessivas iterações.

5.9 de acordo com diferentes números de iterações.

\subsection{Viscosidade variável}

Esta seção apresenta os resultados obtidos levando em conta fluidos com diferentes viscosidades, ou seja, caracterizando uma formulação multifásica. Tais viscosidades são definidas em função da tonalidade de cinza em cada pixel da imagem. Dessa forma, elementos com tonalidades diferentes na imagem representam fluidos diferentes. Isto ocorre de maneira linear, ou seja, sendo $I_{i, j}$ a tonalidade de cinza que um pixel armazena em relação à posição $(i, j)$ da matriz de intensidades, a distribuição de viscosidades é dada por

$$
\nu_{i, j}=a+b * I_{i, j}
$$

onde $a$ e $b$ são constantes pré-definidas pelo programador e $I_{i j}$ assume valores entre 0 e 1 , sendo portanto $a$ e $a+b$ os valores mínimo e máximo, respectivamente, definidos para a viscosidade quando se trabalha com imagens com porções pretas e brancas, respectivamente. Nas simulações que seguem, adotamos $a=0.00001$ e $b=999.99999$. 


\section{Resultados}
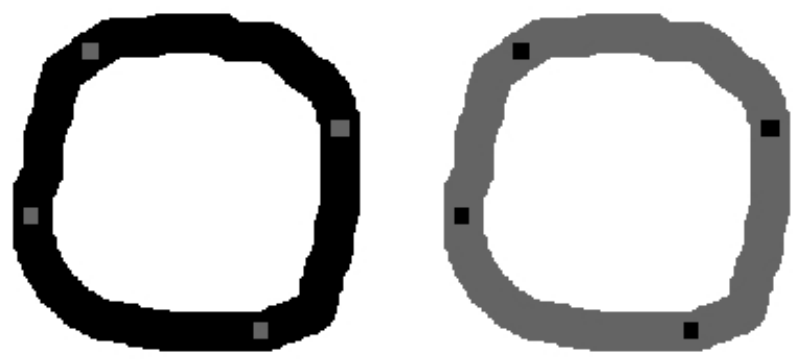

(a) Primeira simulação, (b) Segunda simulação, (c) Terceira simulação, $200 \times 200$ pixels.

$200 \times 200$ pixels.

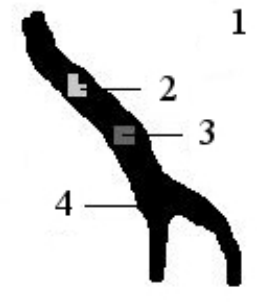

$150 \times 150$ pixels.

Figura 5.15: Imagens consideradas nas simulações.

Para demonstrar os efeitos em imagem de uma simulação cuja viscosidade é variável em nosso contexto, consideramos as imagens apresentadas na figura 5.15. Na figura 5.15(c), os números relacionados indicam o número de tonalidades na escala de cinza (branco região 1, intensidade 255; cinza 1 - região 2, intensidade 200; cinza 2 - região 3, intensidade 100; preto - região 4, intensidade 0), no caso, caracterizando a presença de 4 fluidos com viscosidades diferentes.

Na primeira simulação, envolvendo a figura 5.15(a), adotamos $\Delta t=0.14$ e uma força externa atuando no sistema verticalmente $f_{y}=-10$. Salientamos que essa força age exclusivamente na região escura da imagem e nos pequenos quadrados definidos em seu interior. Em uma segunda simulação, adotamos a imagem da figura 5.15(b) e os mesmos dados da simulação anterior. Como se observa, o que difere ambas imagens é justamente as tonalidades e cinza da porção escura e da que compõe os pequenos quadrados, que são invertidas propositalmente.

As figuras 5.16, 5.17, 5.18 e 5.19 apresentam o perfil das componentes de velocidade e da pressão para a simulação envolvendo a imagem da figura 5.15(a). As figuras 5.20, 5.21, 5.22 e 5.23 apresentam os resultados obtidos à partir da imagem 5.15(b).

As figuras 5.24 e 5.25 apresentam a configuração das imagens 5.2(a) e 5.9, respectivamente, de acordo com o número de iterações mencionado. Nas figuras 5.26, 5.27 e 5.28 estão ilustrados os resultados obtidos à partir da simulação computacional envolvendo a figura 5.15(c). Nesta simulação, consideramos $\Delta t=0.12$ e duas forças distintas agindo verticalmente no sistema, uma de intensidade $f_{y}=-14$ que age sobre as regiões 2 e 4 e 


\section{Resultados}

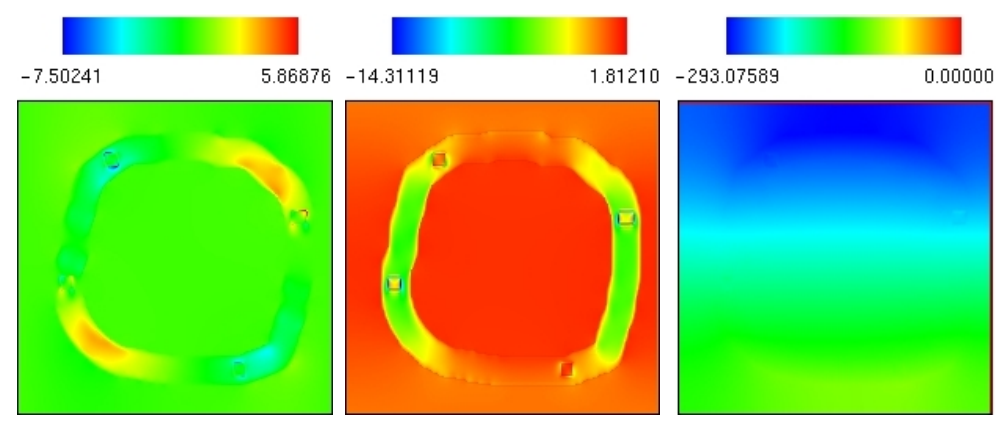

$\begin{array}{ll}\text { (a) Velocidade em } x \text {. (b) Velocidade em } y . & \text { (c) Pressão. }\end{array}$

Figura 5.16: Perfil de propriedades após 10 iterações.

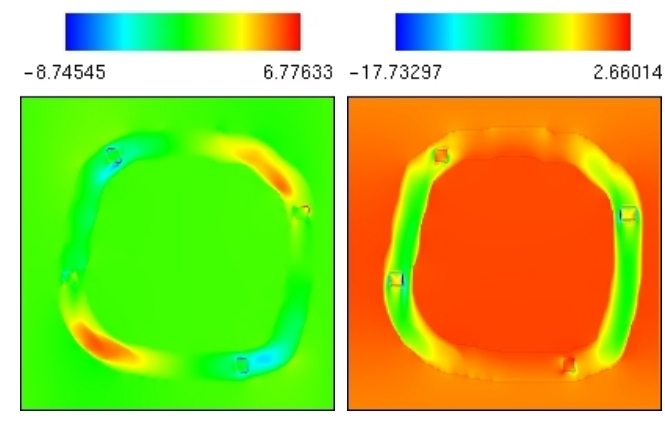

(a) Velocidade em $x$. (b) Velocidade em $y$.

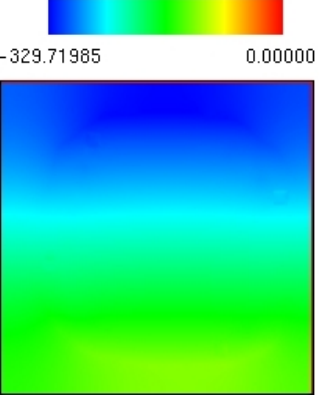

(c) Pressão.

Figura 5.17: Perfil de propriedades após 30 iterações.

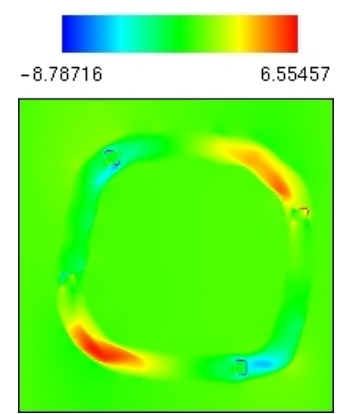

(a) Velocidade em $x$.

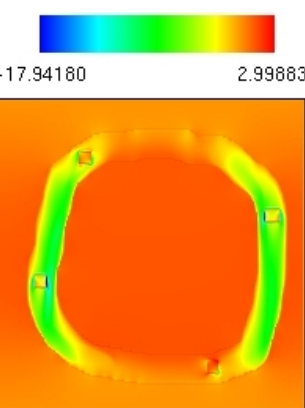

(b) Velocidade em $y$.

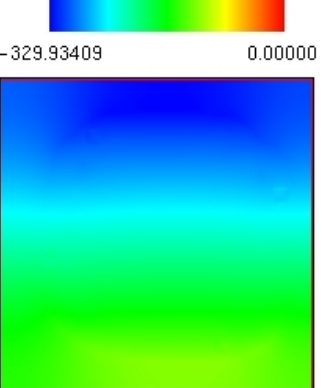

(c) Pressão.

Figura 5.18: Perfil de propriedades após 50 iterações.

outra de intensidade $f_{y}=-10$ que age sobre a região 3 .

Como era de se esperar, a região 3 da imagem deslocou-se por entre o fluido definido pela região escura da imagem mais rapidamente que a região 2. A intensidade da força aplicada diretamente na região 2 não foi suficiente para compensar a viscosidade adquirida inicialmente pela região 3 . 


\section{Resultados}

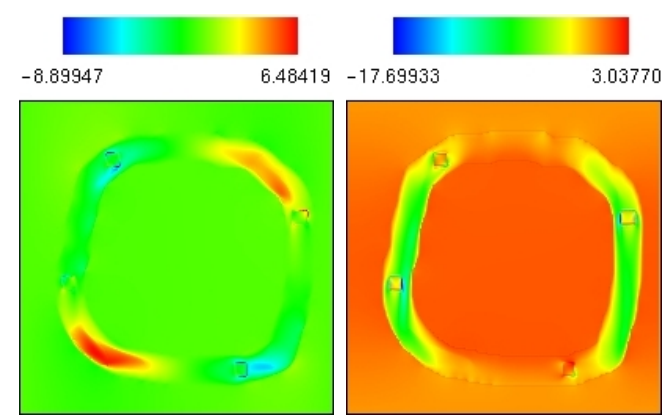

(a) Velocidade em $x$. (b) Velocidade em $y$.

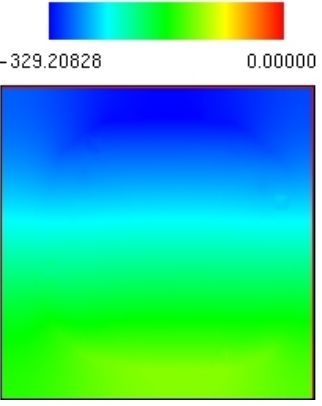

(c) Pressão.

Figura 5.19: Perfil de propriedades após 70 iterações.

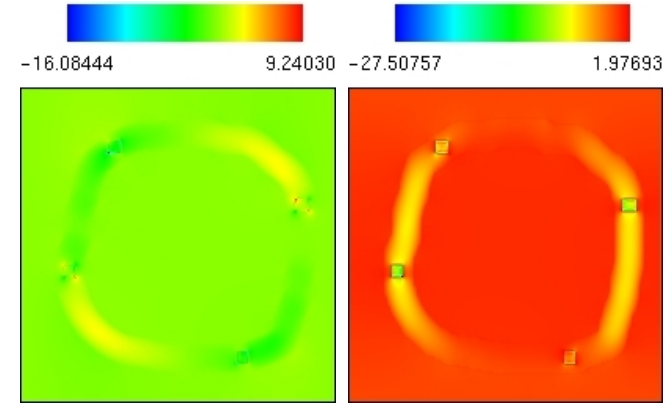

(a) Velocidade em $x$. (b) Velocidade em $y$.

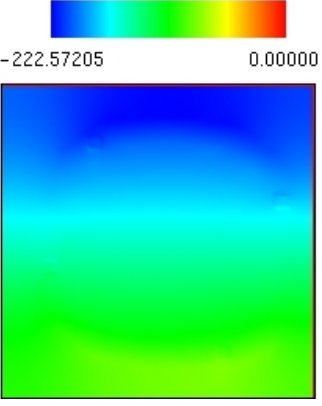

(c) Pressão.

Figura 5.20: Perfil de propriedades após 10 iterações.

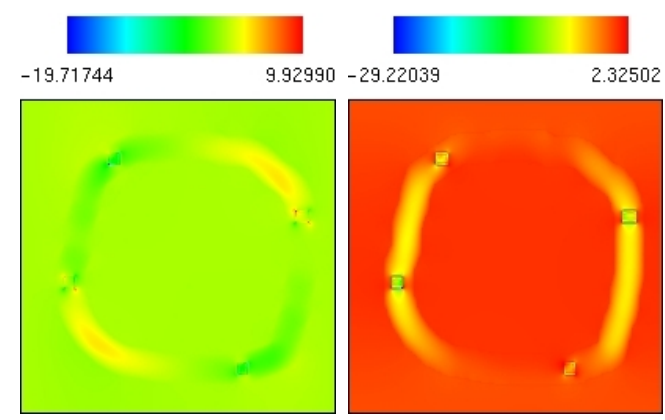

(a) Velocidade em $x$. (b) Velocidade em $y$.

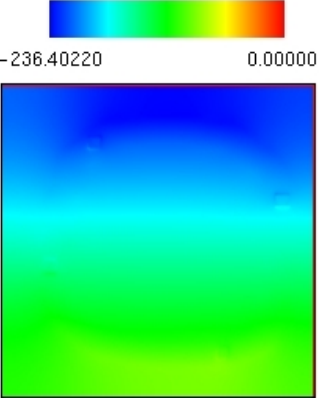

(c) Pressão.

Figura 5.21: Perfil de propriedades após 30 iterações. 


\section{Resultados}

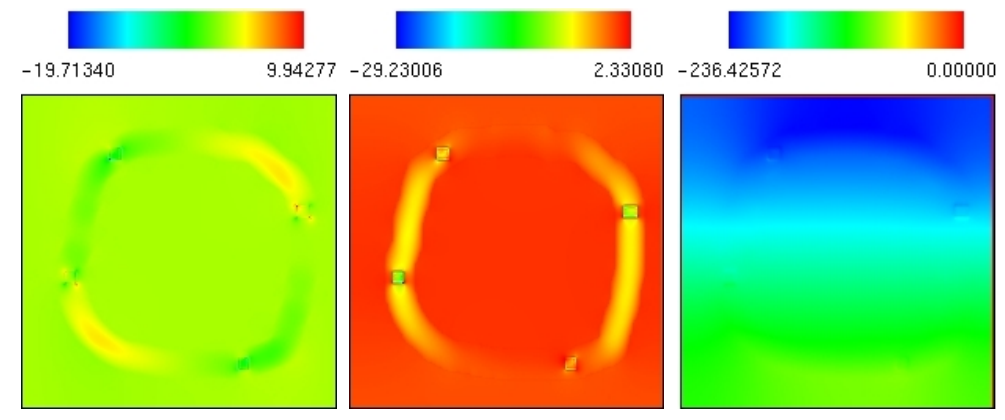

$\begin{array}{ll}\text { (a) Velocidade em } x \text {. (b) Velocidade em } y . & \text { (c) Pressão. }\end{array}$

Figura 5.22: Perfil de propriedades após 50 iterações.

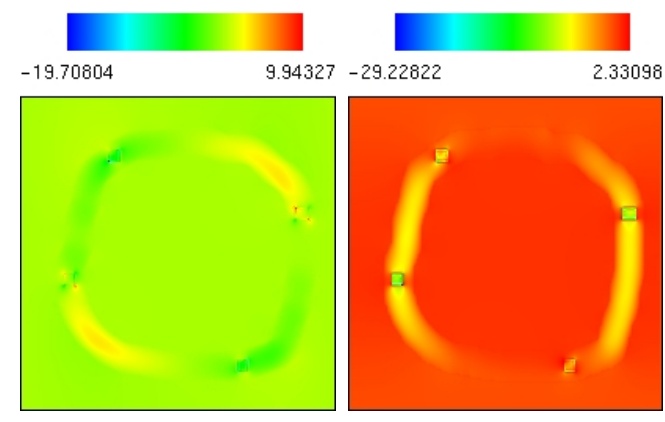

(a) Velocidade em $x$. (b) Velocidade em $y$.

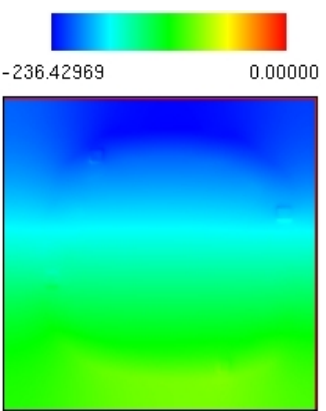

(c) Pressão.

Figura 5.23: Perfil de propriedades após 70 iterações.

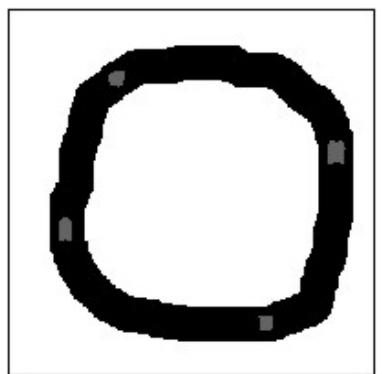

(a) 10 iterações.

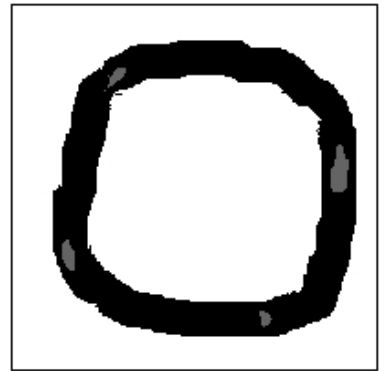

(b) 30 iterações.

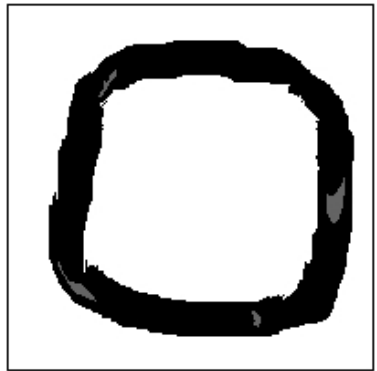

(c) 50 iterações.

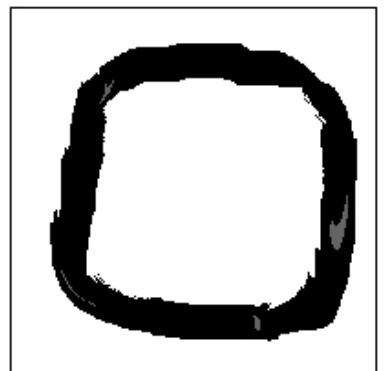

(d) 70 iterações.

Figura 5.24: Evolução da imagem pictoral após sucessivas iterações. 


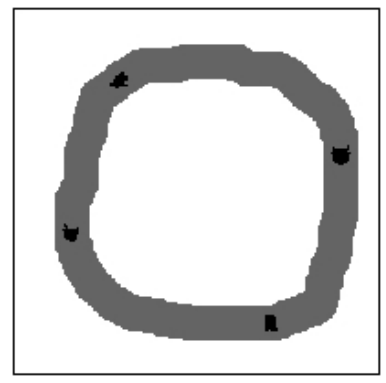

(a) 10 iterações.

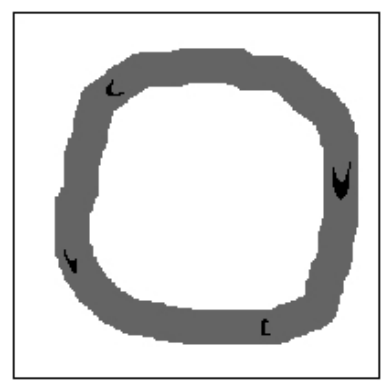

(b) 30 iterações.

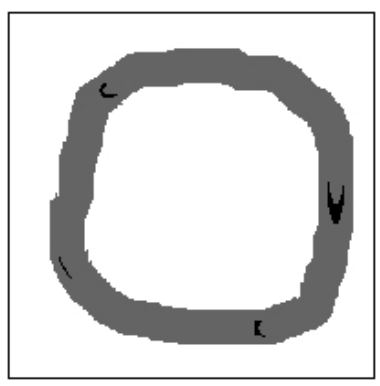

(c) 50 iterações.

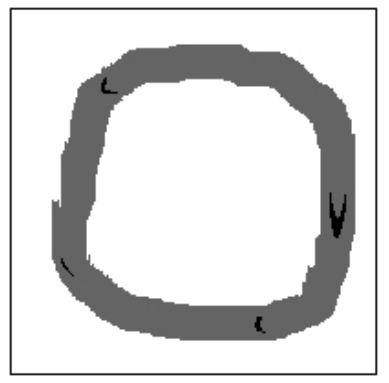

(d) 70 iterações.

Figura 5.25: Evolução da imagem pictoral após sucessivas iterações.

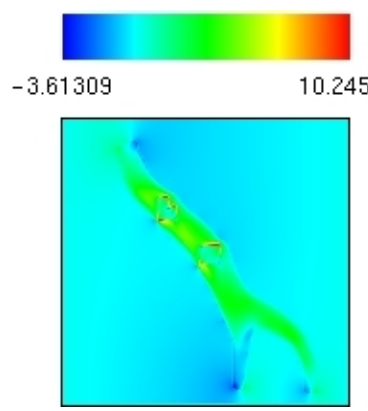

(a) Velocidade em $x$.

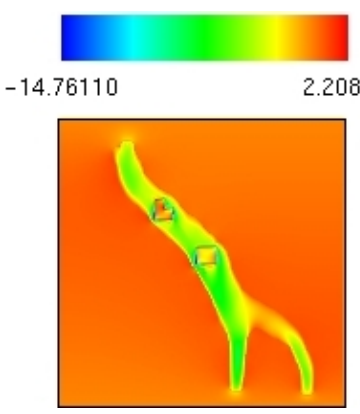

(b) Velocidade em $y$.

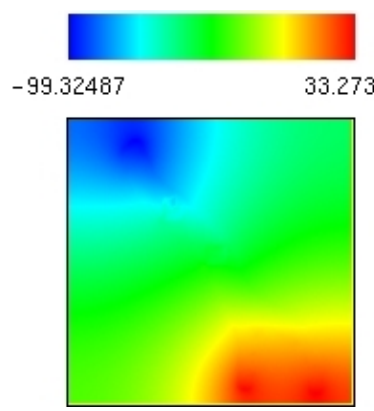

(c) Pressão.

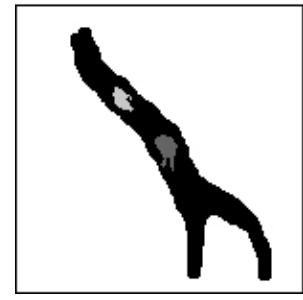

(d) Imagem.

Figura 5.26: Perfil de propriedades e configuração da imagem após 20 iterações.

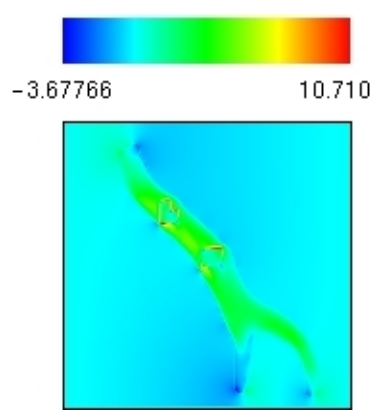

(a) Velocidade em $x$.
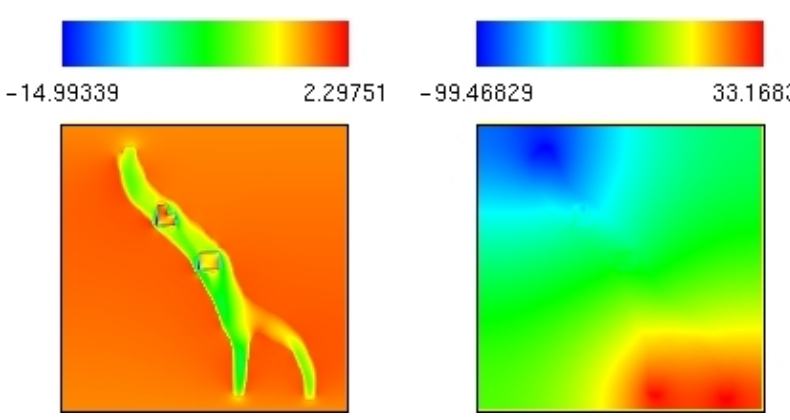

(c) Pressão.

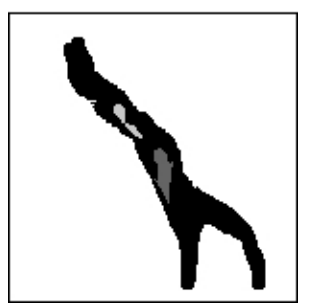

(d) Imagem.

Figura 5.27: Perfil de propriedades e configuração da imagem após 40 iterações. 


\section{Resultados}

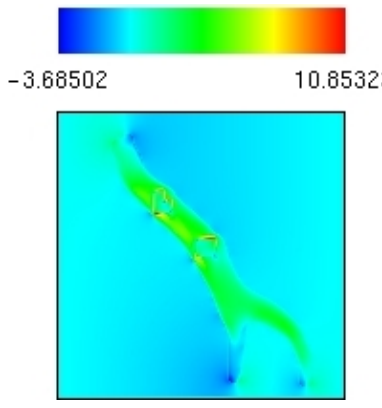

(a) Velocidade em $x$.

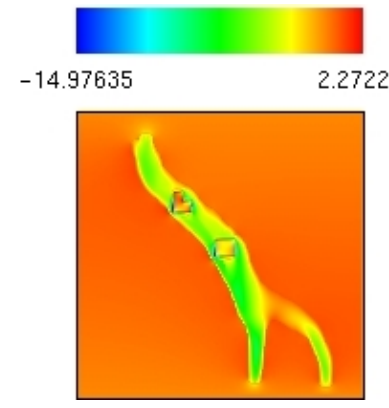

(b) Velocidade em $y$.

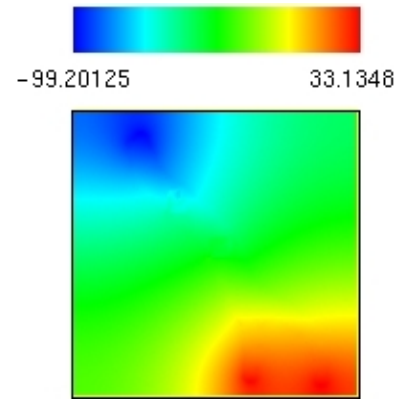

(c) Pressão.

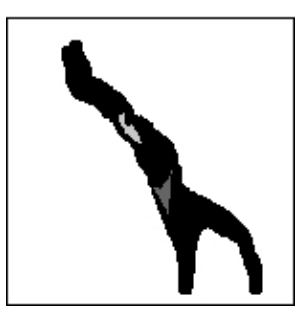

(d) Imagem.

Figura 5.28: Perfil de propriedades e configuração da imagem após 60 iterações. 


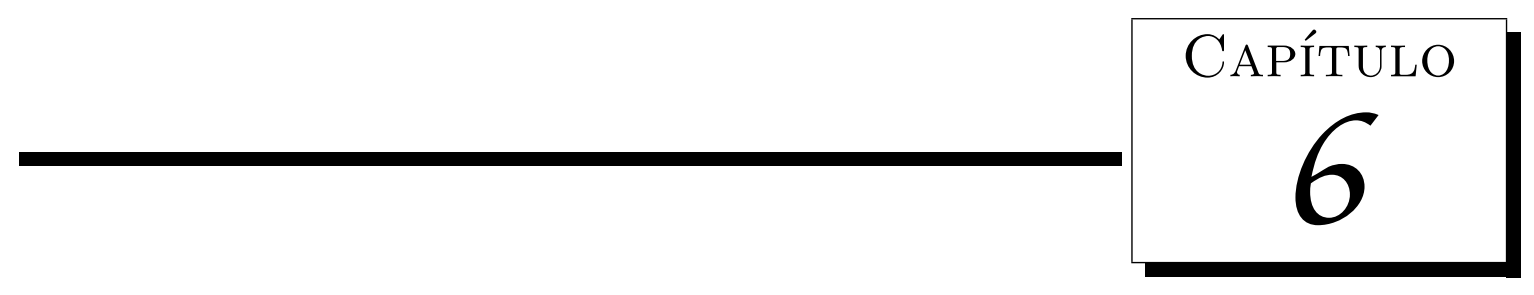

\section{Conclusão}

O estudo da simulação de escoamentos relacionado diretamente ao processamento de imagens ainda é um campo pouco explorado na computação gráfica. O objetivo deste trabalho de mestrado foi implementar um solver de fluidos estável que possibilitasse a simulação de um escoamento multifásico em imagens digitais sem que fosse necessária a conversão dos elementos que as definem em entidades geométricas. Utilizando uma metodologia baseada no método proposto por Stam [30] e no MFI [24] foi possível, portanto, processar imagens digitais utilizando de idéias da dinâmica dos fluidos sem que técnicas específicas de segmentação fossem trabalhadas. 
Conclusão 


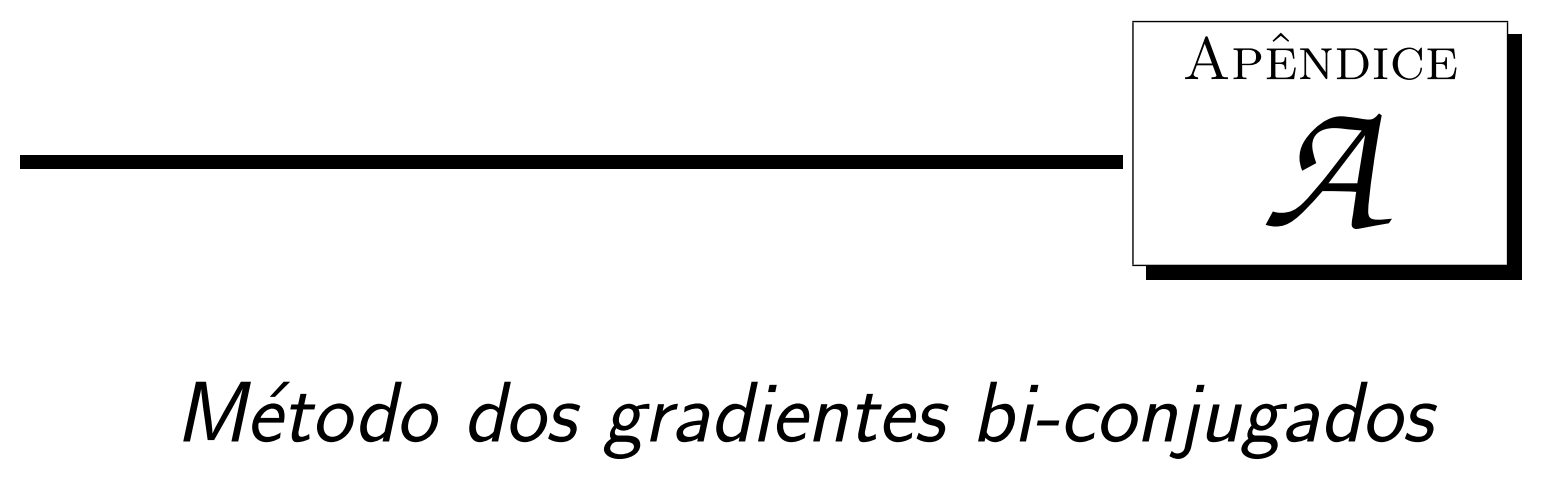

Os métodos dos gradientes conjugados (MGC) têm sido estudados a partir da década de 50, motivados pela solução de sistemas grandes e esparsos provenientes da discretização de equações diferenciais parciais e viabilizados pela entrada dos computadores no cálculo científico. Usam iterações para calcular sucessivas aproximações para a solução do sistema, num processo cuja convergência depende da matriz dos coeficientes $\mathbf{A}$ [8].

O MGC exige que a matriz A do sistema linear seja simétrica e positiva definida, isto é, $\mathbf{A}^{T}=\mathbf{A}$ e $\mathbf{x}^{T} \mathbf{A} \mathbf{x}>0$, para qualquer $\mathbf{x}$ não-nulo. O método dos gradientes bi-conjugados (MGbC) é uma variação do MGC para solução de sistemas lineares na forma $\mathbf{A x}=\mathbf{b}$, onde A é uma matriz não-simétrica.

A formulação do MGbC requer inicialmente a construção de 4 vetores $\mathbf{r}_{k}, \overline{\mathbf{r}}_{k}, \mathbf{p}_{k}$ e $\overline{\mathbf{p}}_{k}$, $k=1,2, \ldots$ Os vetores iniciais $\mathbf{r}_{1}, \overline{\mathbf{r}}_{1}, \mathbf{p}_{1}=\mathbf{r}_{1}$ e $\overline{\mathbf{p}}_{1}=\overline{\mathbf{r}}_{1}$ devem ser fornecidos. Desta forma, os passos do algoritmo consistem na obtenção ordenada dos vetores definidos em (A.1-A.6)

$$
\begin{aligned}
\boldsymbol{\alpha}_{k} & =\frac{\mathbf{r}_{k}^{T} \overline{\mathbf{r}}_{k}}{\overline{\mathbf{p}}} k^{T} \mathbf{A} \mathbf{p}_{k} \\
\mathbf{r}_{k+1} & =\mathbf{r}_{k}-\boldsymbol{\alpha}_{k} \mathbf{A} \mathbf{p}_{k} \\
\overline{\mathbf{r}}_{k+1} & =\overline{\mathbf{r}}_{k}-\boldsymbol{\alpha}_{k} \mathbf{A}^{T} \overline{\mathbf{p}}_{k}
\end{aligned}
$$


Método dos gradientes bi-conjugados

$$
\begin{aligned}
\boldsymbol{\beta}_{k} & =\frac{\overline{\mathbf{r}}_{k+1}^{T} \mathbf{r}_{k+1}}{\overline{\mathbf{r}}_{k}^{T} \mathbf{r}_{k}} \\
\mathbf{p}_{k+1} & =\mathbf{r}_{k+1}+\boldsymbol{\beta}_{k} \mathbf{p}_{k} \\
\overline{\mathbf{p}}_{k+1} & =\overline{\mathbf{r}}_{k+1}+\boldsymbol{\beta}_{k} \overline{\mathbf{p}}_{k}
\end{aligned}
$$

Os vetores dessa sequência são bi-ortogonais, ou seja

$$
\overline{\mathbf{r}}_{i}^{T} \mathbf{r}_{j}=\mathbf{r}_{i}^{T} \overline{\mathbf{r}}_{j}, \quad j<i
$$

e também satisfazem a condição

$$
\overline{\mathbf{p}}_{i}^{T} \mathbf{A} \mathbf{p}_{j}=\mathbf{p}_{i}^{T} \mathbf{A}^{T} \overline{\mathbf{p}}_{j}=0, \quad j<i
$$

e são reciprocamente ortogonais

$$
\overline{\mathbf{r}}_{i}^{T} \mathbf{p}_{j}=\mathbf{r}_{i}^{T} \overline{\mathbf{p}}_{j}=0, \quad j<i,
$$

conforme pode ser visto em [25]. Portanto, para estabelecer um algoritmo à partir das equações (A.1-A.6), um vetor $\mathbf{x}_{1}$ é escolhido e o resíduo inicial tem a forma

$$
\mathbf{r}_{1}=\mathbf{b}-\mathbf{A x}_{1}
$$

com $\overline{\mathbf{r}}_{1}=\mathbf{r}_{1}$. O próximo vetor da sequência de aproximações é dado por

$$
\mathbf{x}_{k+1}=\mathbf{x}_{k}+\boldsymbol{\alpha}_{k} \mathbf{p}_{k}
$$

O critério de parada estabelecido para o método satisfaz

$$
\frac{\left|\mathbf{A} \mathbf{x}_{k+1}-\mathbf{b}\right|}{|\mathbf{b}|}<\mathrm{R}
$$

onde R corresponde a uma tolerância pré-definida pelo usuário de acordo com sua aplicação. 


\section{Referências Bibliográficas}

[1] W. Baxter, V. Scheib e M. C. Lin. Impasto: a realistic model for paint. Proceedings of the 3rd International Symposium on Non-Photorealistic Animation and Rendering, páginas 45 - 46, 2004.

[2] M. Bertalmio, A. L. Bertozzi e G. Sapiro. Navier-Stokes, fluids dynamics, and image and video inpainting. Proceedings of the International Conference on Computer Vision and Pattern Recognition, 1:355 - 362, 2001.

[3] M. Bertalmio e G. Sapiro. Image inpainting. Computer Graphics (SIGGRAPH), páginas 417 - 424, 2000.

[4] R. P. Beyer e R. J. LeVeque. Analysis of a one-dimensional model for the immersed boundary method. SIAM Journal of Numerical Analysis, 29:332 - 364, 1992.

[5] M. T. Cockshott. Wet and sticky: a novel model for computer-based painting. Tese de doutorado, University of Glasgow, UK, 1991.

[6] P. Colella, D. T. Graves, T. J. Ligocki, D. F. Martin, D. Modiano, D. B. Serafini e B. Van Straalen. Chombo software package for adaptive mesh refinement aplications. Lawrence Berkeley National Laboratory, USA, 2003.

[7] R. Courant e D. Hilbert. Methods of Mathematical Physics. Wiley Classic Library, USA, 1953.

[8] M. C. C. Cunha. Métodos numéricos. Editora UNICAMP, Campinas/SP, 2003. 


\section{Referências Bibliográficas}

[9] C. J. Curtis, S. E. Anderson., J. E. Seims, K. W. Fleischery e D. H. Salesin. Computergenerated watercolor. Proceedings of SIGGRAPH 1997, páginas 421 - 430, 1997.

[10] T. Deschamps, P. Schwartz, D. Trebotich, P. Colella, D. Saloner e R. Malladi. Vessel segmentation and blood flow simulation using level-sets and embedded boundary methods. International Congress Series, 1268:75 - 80, 2004.

[11] A. O. Fortuna. Técnicas computacionais para dinâmica dos fluidos. EdUSP, São Paulo/SP, 2000.

[12] D. Goldstein, R. Handler e L. Sirovic. Modeling a no-slip flow boundary with an external force field. Journal of Computational Physics, 105:354 - 366, 1993.

[13] E. Guendelman, A. Selle, F. Losasso e R. Fedkiw. Coupling water and smoke to thin deformable and rigid shells. Proceedings of SIGGRAPH 2005, páginas 973 - 981, 2005

[14] D. Hearn e M. Baker. Computer Graphics, C version. Prentice Hall, University of Illinois, USA, 1997.

[15] P. Kubelka e F. Munk. Ein beitrag zur optik der farbanstriche. Tech. Physik, páginas $593-601,1931$.

[16] T. Van Laerhoven e F. Van Reeth. Real-time simulation of watery paint. Computer Animation and Virtual Worlds, 16:429 - 439, 2005.

[17] M. C. Lai e C. S. Peskin. An immersed-boundary method with formal second order accuracy and reduced numerical viscosity. Journal of Computational Physics, 160:705 $-719,2000$.

[18] D. Marr e E. Hildreth. Theory of edge detection. Proceedings of the Royal Society London, B207:187 - 217, 1980.

[19] R. Mittal e G. Iaccarino. Immersed boundary methods. Annual Review of Fluid Mechanics 2005, 37:239 - 261, 2005. 


\section{Referências Bibliográficas}

[20] J. Mohd-Yosuf. Combined immersed boundary/B-spline methods for simulation of flow in complex geometries. Annual Research Briefs, Center for Turbulence Research, páginas 317 - 328, 1997.

[21] M. Muller, S. Schirm, M. Teschner, B. Heidelberger e M. Gross. Interaction of fluids with deformable solids. Journal of Visualization and Computer Animation, 15:159$171,2004$.

[22] M. Muller, B. Solenthaler, R. Keiser e M. Gross. Particle-based fluid-fluid interaction. Proceedings of the Eurographics Symposium on Computer Animation 2005, páginas $237-244,2005$.

[23] S. Osher e J. Sethian. Fronts propagating with curvature dependent speed: algorithms based on hamilton-jacobi formulations. Journal of Computational Physics, 79:12 49, 1988.

[24] C. S. Peskin. Numerical analysis of blood flow in the heart. Journal of Computational Physics, 25:220 - 252, 1977.

[25] Alfio Quarteroni, Riccardo Sacco and Fausto Saleri. Numerical mathematics. Springer Verlag, USA, 2000.

[26] N. Rasmussen, D. Q. Nguyen, W. Geiger e R. Fedkiw. Smoke simulation for large scale phenomena. Proceedings of SIGGRAPH 2003, 22:703 - 707, 2003.

[27] J. Sethian. Level-set methods and fast-marching methods: evolving interfaces in geometry, fluid mechanics, computer vision and materials sciences. Cambridge University Press, USA, 1999.

[28] D. Small. Modeling watercolor by simulating difusion, pigment and paper fibers. Proceedings of SPIE, 1460:140 - 146, 1991.

[29] F. S. Sousa, N. Mangiavacchi, L. G. Nonato, A. Castelo, M. F. Tomé, V. G. Ferreira, J. A. Cuminato e S. Mckee. A front-tracking/front-capturing method for the simulation of 3D multi-fluid flows with free surfaces. Journal of Computational Physics, 198:468 - 499, 2004. 


\section{Referências Bibliográficas}

[30] J. Stam. Stable fluids. Proceedings of SIGGRAPH 1999, páginas 121 - 128, 1999.

[31] Mark Sussman, Emad Fatemi, Peter Smereka e Stanley Osher. An improved level set method for incompressible two-phase flow. Journal of Computational Physics, 114:146 - 159, 1997.

[32] Mark Sussman, Peter Smereka e Stanley Osher. A level set approach for computing solutions to incompressible two-phase flow. Journal of Computational Physics, 114:146 - 159, 1994.

[33] R. Verzicco, J. Mohd-Yosuf, P. Orlandi e D. Haworth. Large eddy simulation in complex geometries using boundary body forces. AIAA Journal, 38:427 - 433, 1992. 